This item was submitted to Loughborough's Research Repository by the author.

Items in Figshare are protected by copyright, with all rights reserved, unless otherwise indicated.

\title{
Processing of bulk nanostructured ceramics
}

PLEASE CITE THE PUBLISHED VERSION

PUBLISHER

(C) Elsevier

LICENCE

CC BY-NC-ND 4.0

REPOSITORY RECORD

Binner, J.G.P., and Bala Vaidhyanathan. 2008. "Processing of Bulk Nanostructured Ceramics". figshare. https://hdl.handle.net/2134/3259. 
This item was submitted to Loughborough's Institutional Repository by the author and is made available under the following Creative Commons Licence conditions.

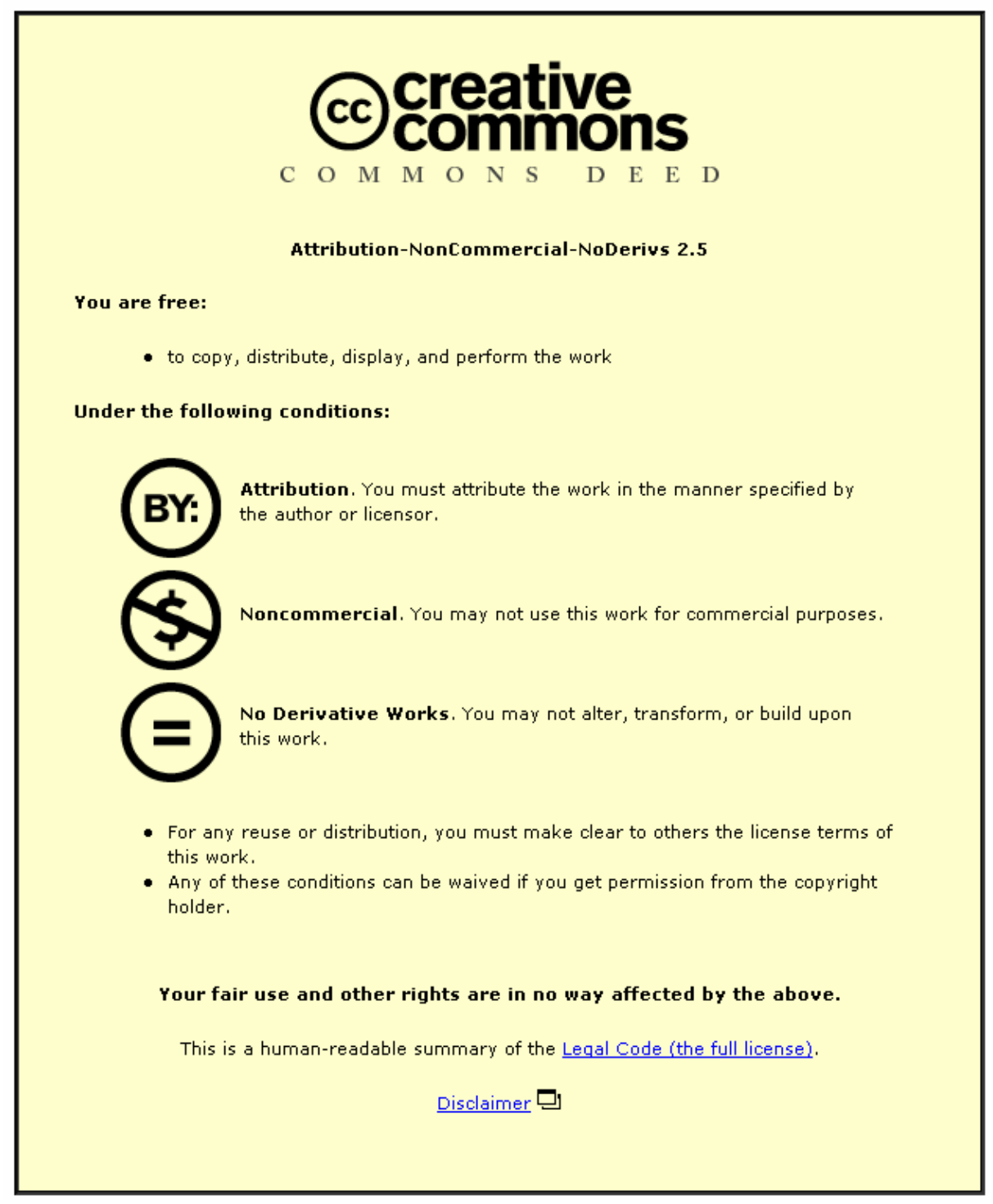

For the full text of this licence, please go to: http://creativecommons.org/licenses/by-nc-nd/2.5/ 


\title{
Processing of Bulk Nanostructured Ceramics
}

\author{
Jon Binner ${ }^{1}$ and Bala Vaidhyanathan \\ IPTME, Loughborough University, UK
}

\begin{abstract}
Conventional ceramic forming routes have been adapted for the processing of $\sim 16 \mathrm{~nm}, 3 \mathrm{~mol} \%$ yttria stabilized zirconia nanopowders leading to the production of $\sim 99 \%$ dense nanostructured ceramics that display average grain sizes as fine as $\sim 65 \mathrm{~nm}$. The precursor material is in the form of $\sim 5 \mathrm{vol} \%$ solids content nanosuspensions produced commercially; these can now be concentrated up to $\sim 37$ vol\% whilst retaining the viscosity at $\sim 0.05 \mathrm{~Pa}$ s. A patent application has been submitted related to the process. The concentrated suspensions have then been used to produce granulated powders suitable for dry forming via spray-freeze drying. Whilst powders have been produced that will yield green bodies with densities of $\sim 50 \%$ of theoretical, currently the powders suffer from either poor flow and low fill densities or granules that are too strong to crush during pressing, even at pressures up to $500 \mathrm{MPa}$. The same suspensions have also been slip cast into extremely homogeneous green bodies with densities of $\sim 54 \%$ of theoretical after drying using a humidity drier. Higher densities are currently blocked by cracking of the samples during drying and/or burnout of the organics if the solids content of the suspensions exceeds $\sim 20 \mathrm{vol} \%$.
\end{abstract}

Radiant and hybrid pressureless sintering experiments have been performed on the dry and wet processed green bodies using both conventional single step and two-step sintering cycles. Whilst densities $>98 \%$ of theoretical were achievable by all combinations, a nanostructure could only be retained using the two stage sintering approach. With hybrid heating the average grain sizes for die pressed samples were in the range $70-80 \mathrm{~nm}$ whilst for the more homogeneous slip cast samples a final average grain size of just 64 $\mathrm{nm}$ was achieved for a body with a final density of $\sim 99.5 \%$. It is believed that the primary advantage offered by hybrid heating is the ability to use a much faster initial heating rate, 20 versus just $7^{\circ} \mathrm{C} \min ^{-1}$, without risking damage to the samples. Whilst detailed characterisation of the properties of these nanostructured ceramics has begun, preliminary results have suggested that the toughness is lower and hardness roughly equivalent to submicron grain-sized 3-YSZ, although the resistance to wear and hydrothermal ageing may have been improved. As a result of detailed crystallographic characterisation

\footnotetext{
${ }^{1}$ Email: j.binner@lboro.ac.uk; tel: +44-1509-223330; fax: +44-1509-223949
} 
this is believed to be due to a grain size dependent shift in the phase boundary composition for nano YSZ ceramics leading to 'over stabilisation' at any given yttria content. Current work is focused on investigating the effect of both yttria content and average grain size on the properties of these new materials.

Keywords: Nanostructure, shaping, sintering

\section{Introduction}

Nanostructured materials, i.e. those with average grain sizes less than $100 \mathrm{~nm}$, have been receiving much attention in recent years. Their appeal is their potential to display unusual physical and mechanical properties as a result of the very high fraction of atoms that reside in the grain boundaries ${ }^{1}$. For example, nanocrystalline ceramics can deform superplastically by grain boundary sliding ${ }^{2,3,4}$; they can display very high magnetoresistance and superparamagnetic properties as well as offering controlled band gaps in electronic materials and transparency for usually opaque materials as a result of the grain size being smaller than the wavelength of light ${ }^{1}$. There are also indications that nanocrystalline ceramics can have extremely low thermal conductivity ${ }^{5}$ whilst Vickers hardness tests have suggested that nanocrystalline ceramics are softer than large grained ceramics at room temperature and so tend to crack less easily ${ }^{6,7}$. Other potential benefits include a reduction in the sintering temperature, allowing metals and ceramics to be co-fired to a greater extent as well as saving energy, whilst the use of nano-sized components will allow devices to be shrunk significantly in size whilst simultaneously increasing their functionality ${ }^{8}$.

However, whilst commercial nanopowders offering these properties have now been produced successfully, sometimes in relatively large quantities, a number of challenges still need to be surmounted if engineering parts are to be manufactured. 'Bottom up' approaches will almost certainly be the longterm solution, however these will not be commercially available for many years - and will require the mainstream ceramic component industry to completely retool. Therefore much current attention is focused on investigating what can be achieved practically via a 'top down' approach based on existing manufacturing facilities. If components can be manufactured without loosing the nanostructure, there is the potential to use these materials for mechanical, thermal, magnetic, electric or electronic applications such as tools, wear and structural parts, magnets, capacitors, varistors and electronic substrates ${ }^{9}$. 
Focusing on ceramic systems, there are three main challenges to achieving the goal of fabricating engineering components from nanopowders ${ }^{1}$, viz:

- The low cost production of quantities of nanopowders with controlled agglomeration;

- The compaction of the particles to achieve flaw-free, homogeneous, high green density bodies prior to sintering (i.e. avoiding cracks, pores and density gradients); and

- The maximisation of densification and minimisation of grain growth during sintering.

This paper will present recent results obtained at Loughborough associated with the green forming and densification of nanostructured zirconia, placing them in the context of ongoing work worldwide. The precursor powder was a $3 \mathrm{~mol} \%$ yttria partially stabilised zirconia (3YSZ) nanpowder with an average particle size of $\sim 16 \mathrm{~nm}$. It was produced by MEL Chemicals in the UK as aqueous suspensions of $\sim 5$ vol\% solids content with no dispersants or other additives present.

\section{Green Forming}

Dry Pressing: Decades of research have shown that the degree of homogeneity of particle packing in the green body has an enormous impact on sintering characteristics. In this regard, nanocrystalline powders are at a severe disadvantage due to the effects of agglomeration. In most dry nanocrystalline powders the crystallites are strongly bonded together to form agglomerates. This leads to both intra-agglomerate and inter-agglomerate porosity, the former generally being at the nanoscale whilst the latter is at the submicron or even micron level, particularly if the powder suffers from multiple levels of agglomeration. By the time that the latter porosity has been eliminated by sintering, grain growth can cause the individual nanoparticles to sinter together yielding a final grain size approximating to that of the original agglomerates ${ }^{10}$. Nevertheless, since the finer the powder the poorer the flow characteristics as a result of the large number of particle-particle contacts, if dry forming, industry's preferred manufacturing route, is to be used for the production of nanostructured ceramics then some degree of agglomeration is going to be required.

Spray dried nanostructured ceramic powders are currently available from a small number of companies. However, probably due to the extremely high surface area of the powders, the agglomerates tend to be extremely strong. This means that whilst they flow very readily and yield die fill densities as good, or almost as good, as those for conventional submicron powders, the agglomerates simply don't crush at 
anything like conventional pressing pressures. Figure 1 shows the microstructure of a body formed by die pressing a commercial, spray dried barium titanate nanopowder at $500 \mathrm{MPa}$ (more than double the pressure typically used in industry). Note that the powder had been ground in a high energy mill (McCrone Micronising Mill, McCrone Research Associates, London, UK) for 7 minutes before pressing and yet the residual agglomerates can still be seen in the microstructure.

The key to success will therefore be the production of 'soft' agglomerates that crush during the die or isostatic pressing process. At Loughborough attention has been focused on spray-freeze drying, where the nanosuspensions are sprayed into liquid nitrogen and then the frozen water sublimed off by heating at low pressure. A VirTis ${ }^{\circledR}$ Benchtop 2K spray-freeze dryer (SP Industries, Gardiner, NY, USA) is used; it involves pouring the freshly ultrasonicated (and thus thoroughly homogeneous) suspension into liquid nitrogen via an ultrasonic rod; the latter breaking up the suspension into droplets which drop into a beaker of liquid nitrogen. The frozen granules are then transferred to a vacuum dryer which operates at $\sim 13.3 \mathrm{~Pa}$ (100 milliTorr) and $-50^{\circ} \mathrm{C}$; drying of the granules via sublimation of the water taking $\sim 2$ days.

The results showed that the solids content of the precursor nanosuspension was crucial for producing a flowable, crushable, dry nanopowder. To achieve different solids contents, the as-received suspension was concentrated to yield nanosuspensions with solids loadings up to $\sim 34$ vol\% but with viscosities as low as $\sim 0.2$ Pa s; details of the process are being published elsewhere and a patent application has been submitted and published ${ }^{11,12}$. In brief, the process relies on modification of the precursor suspension $\mathrm{pH}$ using solid tetramethylammonium hydroxide, TMAH (Aldrich Chemicals Ltd, Dorset, UK), followed by the use of triammonium citrate, TAC (FSA Laboratory, Loughborough, UK), as a dispersant combined with the use of multistage ultrasonics to break up any agglomerates that were present. Concentration was achieved by evaporation at $60^{\circ} \mathrm{C}$; the duration of the process dictating the final solids content which was determined by drying out a precisely known volume of the suspension and then heating it to $700^{\circ} \mathrm{C}$ to remove all traces of the organics and obtaining the mass of ceramic powder present.

Figures $2 \mathrm{a}$ and $\mathrm{b}$ show the granule structures, at different levels of magnification, formed by spray-freeze drying the 3 YSZ nanosuspension at the 3 different solids contents indicated; they are similar to those reported by Tallon et al. ${ }^{13}$ for spray-freeze dried $\gamma$-alumina. It can be seen that the higher the solids content the denser the packing of the particles in the granules, matching the trend observed by Koh et al. ${ }^{14}$ 
for freeze cast ceramic bodies. Both the flow rate, as measured using a Hall flowmeter, and the fill density of the powders varied significantly. Figure 3 shows the flow rates for the same three spray-freeze dried nanopowders and compares them to the flow rates for a spray dried powder made from the 5 vol\% nanosuspension and a benchmark submicron 3YSZ powder (grade TZ-3YSB-C, Tosoh Europe, Amsterdam, Netherlands) that had an average crystallite size of $370 \mathrm{~nm}$ according to the manufacturer. It can be seen that the 28 vol\% spray-freeze dried nanosuspension exhibited a similar flow behaviour to the benchmark and 5 vol\% spray dried nanosuspension, but with lower solids contents the flowability dropped significantly. A similar result was obtained in terms of the die fill density. Values of $0.22,0.65$ and $1.24 \mathrm{~g} \mathrm{~cm}^{-3}$ were obtained for the 5,14 and $28 \mathrm{vol} \%$ solids content nanopowders respectively; the benchmark submicron powder also yielding a value of $1.24 \mathrm{~g} \mathrm{~cm}^{-3}$. These results suggest that, on the basis of these two indicators, the powder formed from the $28 \mathrm{vol} \%$ solids content nanosuspension yielded adequate performance. In addition, green densities of between $50-55 \%$ of theoretical were obtained for all of the spray-freeze dried nanopowders.

A major problem with the powders was that the granules formed were simply too strong when the solids content exceeded $\sim 14$ vol\%. Figures $2 \mathrm{c}$ show fracture surfaces for green bodies formed from 3 sprayfreeze dried powders by die pressing at $380 \mathrm{MPa}$. The existence of a significant fraction of uncrushed granules may be clearly observed in the microstructure for the 28 vol\%-based powder body whilst debris on the surface of that produced from 14 vol\%-based powder may also be from residual granules. This result is confirmed by the results of mercury intrusion porosimetry on the die pressed green bodies, figure 4. This shows data for the $5 \mathrm{vol} \%$-based spray-freeze dried powder in comparison with a spray dried powder made from the same nanosuspension. The latter exhibits both inter- and intra-agglomerate porosity since the spray dried granules formed simply did not crush, fig $4 \mathrm{~b}$, whilst this porosity is largely absent in the spray-freeze dried powder, see fig $2 c$. This result, that porous granules with reduced granule densities crush at lower compression forces and that the resulting bodies are devoid of large residual inter-granular pores, has been shown before for a range of different systems ${ }^{15,16,17}$.

A preliminary analysis of the strength of 50 individual granules from a range of different solids content suspensions has been undertaken at the Fraunhofer Institut Keramische Technologien und Systeme in Dresden, Germany, using a Manual Granulate Strength Testing System (etewe GmbH, Karlsruhe, 
Germany). The equipment initially measures the diameter of each granule and then crushes it using piezoelectric actuators at a fixed speed of $10 \mu \mathrm{m} \mathrm{s}^{-1}$, piezoelectric sensors yielding a force-deformation plot. The results of the measurement are shown in figure 5, where region A represents the elastic / plastic deformation of the granules, point $\mathrm{B}$ the fracture of the granules and region $\mathrm{C}$ the deformation of the fractured pieces. Whilst this data apparently confirms that the higher the solids content of the initial nanosuspension the stronger the granules formed, it should be noted that only 50 granules were tested across all 8 nanosuspensions and that no account of granule size has yet been taken. This has led to a significant degree of scatter in the results which needs refining via further measurements; this work is in hand.

Calculations ${ }^{18}$ of the inter-particle distance in the spray-freeze dried granules (assuming simple cubic packing) have indicated that the separation distance between the nanoparticles would decrease from about $23 \mathrm{~nm}$ in the $5 \mathrm{vol} \%$-based granules to just $4.5 \mathrm{~nm}$ in the $28 \mathrm{vol} \%$-based granules. This reduction in spacing will increase the short range van der Waals forces. Use of Rumpf's model ${ }^{19}$ suggests that the rupture stress of the granules would be $\sim 13$ times higher for the $14 \mathrm{vol} \%$ and $\sim 175$ times higher for the 28 vol\%-based granules compared to the granules produced from the 5 vol $\%$ nanosuspension ${ }^{18}$. However, these forces are still too small in magnitude to be accounted for the persistence of the granular structure at the high consolidation pressures used.

Although no TEM evidence has been obtained yet in the present work, one of the well established reasons for the formation of hard granules in zirconia is bridging by hydrogen bonds. Due to surface hydrolysis, hydroxide is formed on the surface of particles that reprecipitates on drying and cements the particles together, particularly at high and low $\mathrm{pH}^{20}$. As the nanoparticles are packed closer together, the chances of such cementing increases. A detailed study of the granule chemistry using infra red spectroscopy and hydrogen NMR has not yet been started.

Wet forming: These techniques, including slip and gel casting amongst other, offer distinct advantages over dry pressing routes, viz. the ability to sediment out hard agglomerates and the potential for much more homogeneously packed green bodies due to the greater ease with which particles can slide over one another and rearrange in the wet state. In addition, and very importantly, the surface chemistry of ceramic 
particles in suspension can be systematically altered to encourage the particles to arrange themselves in orderly, packing efficient configurations. The primary disadvantage for wet forming routes is the very high viscosities that arise even at low solids contents due to the short interparticle distances and the resultant strength of the interparticle forces.

The same low viscosity, high solids content 3YSZ nanosuspensions used for the spray-freeze drying outlined above, were also slip and gel cast into green bodies. Slip casting was performed using standard plaster of paris moulds forming either cup $(10 \phi \times 10 \times \sim 1 \mathrm{~mm}$ wall thickness $)$ or rectangular $(40 \times 10 \times 3$ $\mathrm{mm}$ ) green bodies which were subsequently dried at room temperature either with or without control of the humidity during the process. Gel casting was performed using up to $6.5 \mathrm{wt} \%$ additions of an aqueous solution of monomers containing $29 \%$ of ammonium acrylate monomers and $1 \mathrm{wt} \%$ of methylenebisacrylamide monomers (Ciba Specialty Chemicals, Bradford, UK). The polymerisation process was performed using chemical initiation by the redox pair persulfate-diamine. The initiator was ammonium persulfate (APS, Aldrich, Gillingham, Dorset, UK) prepared at a concentration of $0.52 \mathrm{~g} \mathrm{ml}^{-1}$ and the catalyst N,N,N',N'-tetramethyl ethylene diamine (TEMED, Aldrich, Gillingham, Dorset, UK). The gel casting route was unsuccessful for all concentrations of gel forming agents used. Although well formed green bodies were produced, they all lost strength very significantly on drying resulting in bodies that could not be handled without them falling apart. It should be noted, however, that related work performed on the gel casting of a commercial nano barium titanate powder and using a different gelation system was more successful in producing handleable green bodies $^{21}$; although in this case the quality of precursor nanopowder was much lower than the nano 3YSZ used in the present work.

When the 3YSZ nanosuspensions were slip cast, very homogeneous green bodies were formed, figure 6, however cracking was found to be a major problem during drying and/or organic burnout of the bodies produced from the higher solids content nanosuspensions. This problem has been encountered elsewhere ${ }^{22}$ and 'solved' by introducing submicron particles to the suspension, which will have opened up the diameter of the pore channels in the green body. However, this rather defeats the objective of producing genuinely nanostructured ceramics. With conventional drying, the maximum solids content bodies that could be dried and burnt out without any visible cracking was $\sim 14$ vol $\%$, however when 
humidity drying was used, suspensions with solids contents of up to $20 \mathrm{vol} \%$ could be slip cast and dried without cracks being observed in the bodies.

Slip cast samples were produced using 14, 20.5 and 24 vol\% solids content nanosuspension and then dried using a humidity dryer (Delta 190H, Design Environmental Ltd, Gwent, UK) under a range of conditions from 50 to $90 \%$ relative humidity and 25 and $30^{\circ} \mathrm{C}$, followed by a 3 step organic burn out heating profile at 100,200 and $500^{\circ} \mathrm{C}$ soaking temperatures using a $1^{\circ} \mathrm{C} \mathrm{min}^{-1}$ heating rate from $\mathrm{RT}$. Whilst too low a humidity resulted in the bodies cracking, too high a humidity resulted in the bodies not being fully dry even after 7 days. The optimum conditions identified to date are $80 \%$ relative humidity at $25^{\circ} \mathrm{C}$; no visible cracks or microcracks are observable in the dried bodies - although drying does take 2 days. Further work will start very soon focusing on measuring the mass of the body during drying with a feedback loop to the dryer allowing the humidity to be varied during the drying process and so creating a rate controlled drying profile.

The higher solids contents not only allowed higher green density bodies to be achieved, up to $\sim 54 \%$ of theoretical, but also resulted in a finer pore structure, figure 7, that, in turn, resulted in higher sintered densities for the same sintering conditions.

It is interesting, and unlikely to be a coincidence, that the limit for successful production of compactable spray-freeze dried powders was nanosuspensions with a solids loading of around $14 \mathrm{vol} \%$ whilst the limit for successful drying of slip cast bodies without the use of a humidity drier was about $12 \mathrm{vol} \%$ (20 vol\% when a humidity drier was used and optimised). Clearly, the solids content of the nanosuspension significantly affects the packing density in the body formed, whether by spray-freeze drying into agglomerates or slip casting into green bodies. This affects both the pore size distribution in the bodies and the strength of the interparticle bonding. This is forming the basis behind future work on the green forming of components by both wet and dry routes.

\section{Densification}

Whilst similar densification phenomena occur as for conventional micron-sized powders ${ }^{23}$, the temperatures required are consistently lower; sintering may start at $\sim 0.2$ of the absolute melting point 
( $\mathrm{T}_{\mathrm{mpt}}$ ) compared to $\sim 0.5 \mathrm{~T}_{\mathrm{mpt}}{ }^{9}$. This generates many potential benefits, including the avoidance of undesirable phase transformations and interfacial reactions, the elimination of the need for sintering aids and the opportunity to produce bonded or graded materials from combinations incompatible at high sintering temperatures, e.g. ceramics and low melting point metals. The specific challenges related to the high reactivity of the powders include the potential for contamination and grain coarsening. Success in avoiding the latter is related to control of the competition between densification and grain growth, something that is extremely difficult because the driving forces for both are proportional to the reciprocal grain size and hence comparable in magnitude. Successful approaches that have been developed include:

- The addition of solutes or $2^{\text {nd }}$ phase particles that reduce grain boundary mobilities or pin them; however this is limited to additives that do not negatively affect the desired properties of the final product $^{24,25}$ and so can be a major limitation for many ceramic systems.

- Very rapid firing; however this requires a) extremely homogeneous green compacts since local variations in green density lead to regions of the same compact being at different locations on the sintering curve and b) physically small-sized components to avoid excessive thermal gradients ${ }^{26}$. Both of these can be considered to be significant limitations.

- Pressure-assisted techniques; although techniques such as hot pressing, hot isostatic pressing, sinter forging and the mis-named spark-plasma sintering have been used very successfully for the

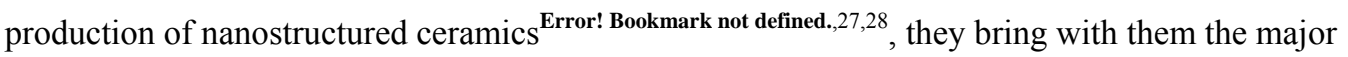
disadvantages of high processing costs combined with limited component shape capability.

- Two-step sintering; this exploits the difference in kinetics between grain boundary diffusion and migration $^{29}$ and combination with microwave heating has proved particularly successful ${ }^{30}$.

The term 'two-step sintering' was first used by Lin et al. ${ }^{31}$ for the microstructural refinement of alumina. They heated $\mathrm{Al}_{2} \mathrm{O}_{3}$ powder compacts to $800^{\circ} \mathrm{C}$ for $50 \mathrm{hr}$ in a precoarsening step and then increased the temperature to $1450^{\circ} \mathrm{C}$ for final sintering, the results being compared with samples sintered without the precoarsening step. It was observed that the microstructure of the precoarsened compacts were more uniform and, for the same density, the amount of closed porosity was lower in the case of the precoarsened $\mathrm{Al}_{2} \mathrm{O}_{3}$. Furthermore, a measurably higher final density, a smaller average grain size and a narrower distribution in grain sizes were achieved with the two-step technique. The microstructural refinement that was produced by the two-step sintering technique was explained in terms of a reduction in 
the effects of differential densification and the resulting delay of the pore channel pinch-off to higher density. Subsequently, a similar approach was used for the sintering of silicon nitride ceramics with bimodal microstructure without the use of $\beta-\mathrm{Si}_{3} \mathrm{~N}_{4}$ seed crystals ${ }^{32}$. In the process, the first step suppressed densification whilst allowing the $\alpha$-to- $\beta$ phase transformation to proceed whilst the second step, again at higher temperatures, promoted densification and grain growth.

The concept of two-step sintering changed radically with the work of Chen et al. ${ }^{29,33}$ for the sintering of nanostructured $\mathrm{Y}_{2} \mathrm{O}_{3}$ ceramics. This time the green compacts were initially heated to a high temperature (e.g. 1250 or $1310^{\circ} \mathrm{C}$ ), known as $\mathrm{T} 1$, for a very short time and then cooled down rapidly to a lower temperature (e.g. $\left.1150^{\circ} \mathrm{C}\right), \mathrm{T} 2$, where they were held until complete densification was achieved; this period typically taking around 20 hours. The key attribute of the process was that no grain growth was reported during the hold at $\mathrm{T} 2$, figure $3 \mathrm{a}$, provided that a sufficiently high density (e.g. $>70 \%$ for the nano $\mathrm{Y}_{2} \mathrm{O}_{3}$ ) was obtained during the first step. This lack of grain growth, or 'frozen microstructure' during the second step whilst densification continued was argued to be consistent with a grain boundary network pinned by triple-point junctions that have a higher activation energy for migration than the grain boundaries. Thus the feasibility of densification without grain growth was thought to rely on the suppression of grain-boundary migration whilst keeping grain-boundary diffusion active.

The authors also suggested ${ }^{\text {Error! Bookmark not defined.,33 }}$ that there was a kinetic window for the second step and that it spanned a wider temperature range with increasing grain size, figure $8 \mathrm{~b}$. At temperatures above the kinetic window, grain growth occurred for which the driving force diminished as the grain size increased. At temperatures below the kinetic window, sintering was exhausted before full density was achieved. However, fully dense samples did not resist grain growth indefinitely at $\mathrm{T} 2$; the grain size was found to increase after a long enough 'incubation period'. The effect of dopants on the second stage of sintering was also found to be in agreement with observations made during single stage sintering of yttria, viz. magnesium enhancing kinetics and niobium depressing them.

Subsequent work by the same team focused on the two-step sintering of $10 \mathrm{~nm} \mathrm{BaTiO}{ }_{3}$ and $\mathrm{Ni}-\mathrm{Cu}-\mathrm{Zn}$ ferrite powders ${ }^{34}$, the green bodies being prepared by die pressing followed by isostatic pressing. In both cases, the two step sintering schedule reduced grain growth by up to an order of magnitude, though only 
one of the $\mathrm{BaTiO}_{3}$ ceramics reached as high as $98 \%$ of theoretical density whilst the ferrite samples all ended up with average grain sizes significantly larger than $100 \mathrm{~nm}$. When a different $\mathrm{BaTiO}_{3}$ nanopowder was two-step sintered by other researchers ${ }^{10}$, grain growth was observed during the $2^{\text {nd }}$ stage of sintering with the average final grain size of the fully dense ceramics being around $1000 \mathrm{~nm}$. This was probably due to the very agglomerated nature of the precursor nanopowder. In the case of $\beta$-SiC nanopowders, a final grain size of just $40 \mathrm{~nm}$ was claimed for $99 \%$ dense, two-step sintered powders with a mean particle size of $\sim 20 \mathrm{~nm}^{35}$, though the microstructure of the 'best' ceramic looks to contain much more than $1 \%$ porosity. When submicron alumina powder was two-step sintered ${ }^{36}$, although the grain growth in the final stage was not suppressed entirely the final average grain size was roughly half of that achieved when the same material was sintered conventionally suggesting that 2-step sintering was applicable to 'conventional' submicron ceramics as well as nanostructured ceramics. Complete elimination of residual porosity was prevented by the presence of hard agglomerates in the green body.

In the work at Loughborough, $\sim 50 \%$ dense $3 \mathrm{YSZ}$ green bodies prepared by both die pressing and slip casting were sintered using both a single step and two step sintering approach; these are illustrated schematically in figure 9 . The conventionally sintered samples were heated at $7^{\circ} \mathrm{C} \mathrm{min}^{-1}$ to a sintering temperature $T_{1}$ and held for up to 8 hours and then furnace cooled back to room temperature. The two stage sintered samples were heated at the same $7 \mathrm{~min}^{-1}$ to an initial temperature, $\mathrm{T}_{1}$, but after only 0.1 minutes immediately cooled back down to temperature $\mathrm{T}_{2}$ as rapidly as possible before holding for periods of up to 30 hours. For the single stage sintered samples, $\mathrm{T}_{1}$ was varied from 900 to $1150^{\circ} \mathrm{C}$ whilst for the two stage sintered samples $\mathrm{T}_{1}$ was always $1150^{\circ} \mathrm{C}$ and $\mathrm{T}_{2}$ was varied between 1000 and $1050^{\circ} \mathrm{C}$. Sintering was performed using a hybrid microwave / radiant sintering furnace that could be operated in either pure radiant or hybrid microwave/radiant mode. The microwave frequency was $2.45 \mathrm{GHz}$; up to 2 $\mathrm{kW}$ of microwave power was available. In the work reported here, a fixed level of $600 \mathrm{~W}$ of microwaves was used throughout the sintering cycle for the hybrid heated samples, with the amount of radiant power being varied to yield the desired temperature-time profile. The temperature was measured and controlled using optical thermometry (Orbis Technologies, USA), which previous work has shown is the most accurate method $^{37}$. Corroborative temperature distribution measurements were performed using a thermal imaging camera (FLIR Systems Thermovision ${ }^{\circledR}$ A40, USA). After sintering, the samples were characterized in terms of their densities, using the Archimedes technique in deionised water, and their 
grain size, after gold coating, using a field emission gun scanning electron microscope (FEG-SEM) and the procedure followed that laid out in British Standards ${ }^{38}$.

The average grain size of the sintered nanostructured bodies is plotted as a function of sample density in figure 10, whilst representative micrographs of the structures at three different points on the sintering curves, labelled a, b and c, are shown in figure 11. Two results are immediately observable; the first is that the use of hybrid heating has consistently resulted in a finer average grain size for a given final density and the second is that the use of two stage sintering successfully resulted in the ability to retain a very fine grain size, whilst achieving effectively full densification. With radiant heating, there was a steady increase in grain size up to around $90-95 \%$ of full density when there was a sharp increase in grain size. This fits with the closing of the porosity, when grain growth generally becomes significant. The use of two stage sintering, however, clearly reduced grain growth whilst allowing densification to continue occur. Like Chen and Wang ${ }^{29}$, it was observed that to succeed in two-stage sintering a density $\geq 75 \%$ of theoretical had to be obtained during the first stage, the benefit arising from this level of densification being related to the pores, which became subcritical and so unstable against shrinkage, rather than the density value itself.

The use of hybrid heating can be seen to have resulted in a much finer average grain size at all densities. Although recent results from Binner et al have now confirmed the existence of the so-called 'microwave effect' during ceramic sintering ${ }^{39,40}$, it is believed that the major effect influencing these results is that a much faster heating rate was used. Due to the volumetric nature of the hybrid heating, $20^{\circ} \mathrm{C} \mathrm{min}^{-1}$ could be used without risking any damage to the samples from thermal stresses, whilst the radiant heating was limited to only $7^{\circ} \mathrm{C} \min ^{-1}$ if cracking was to be avoided. Since, as indicated by Chen et al. ${ }^{29}$, the bulk of the grain growth that occurs during two stage sintering is during the initial heating to $\mathrm{T} 1$, the faster this stage can occur, the smaller the amount of grain growth overall. As for the radiantly heated samples, the rapid increase in grain growth began at densities of $90-95 \%$; achieving full density resulted in average grain sizes $\geq 160 \mathrm{~nm}$. However, the combination of hybrid heating with the two stage sintering technique clearly resulted in the ability to retain a final grain size in the range $60-80 \mathrm{~nm}$ whilst achieving densities in excess of $99 \%$. Figure 12 illustrates the homogeneity that was achieved across the entirety of a sample. The density was $\sim 99.5 \%$ of theoretical and the average grain size was $64 \mathrm{~nm}$. 
Finally, it can be seen in figure 10 that the $2^{\text {nd }}$ stage grain size - density line is curved in a similar manner to the single stage sintering data but with a significant increase in average grain size occurring at densities above about $97 \%$ of theoretical. This suggests that the operative mechanism during two stage sintering may be essentially the same as during conventional sintering but the densification curve is pushed to the right by the samples effectively having a much higher green density than would be normal for ceramic sintering. Further work is needed to clarify this situation.

\section{Conclusions}

Both wet and dry forming of nanostructured 3YSZ ceramics have been investigated using precursor aqueous suspensions of $\sim 16 \mathrm{~nm}$ particles. As-received, these had a solids content of $\sim 5 \mathrm{vol} \%$ and a $\mathrm{pH}$ of 2.5. After modifying the suspension $\mathrm{pH}$ using solid tetramethylammonium hydroxide, triammonium citrate was found to be a suitable dispersant when combined with the use of multistage ultrasonics to break up any agglomerates that were present. This permitted the suspension to be concentrated by evaporation at $60^{\circ} \mathrm{C}$; the duration of the process dictating the final solids content. Suspensions with solids contents as high as 37 vol\% but viscosities as low as $0.05 \mathrm{~Pa}$ s were produced. These were subsequently used to produce both spray dried and spray-freeze dried powders for use in die pressing and also slip and gel cast into green bodies.

For the dry forming route, when spray drying of the as-received suspensions was performed, a free flowing granulated powder was formed that exhibited a fill density approximately the same as a benchmark commercial submicron powder but the granules were too strong and so did not crush even at die pressing pressures of up $500 \mathrm{MPa}$. The product arising from the use of a spray-freeze drying route was found to depend very significantly on the solids content of the suspension used. At low solids contents, below $\sim 14$ vol\%, the granules formed were weak enough to crush leaving no trace in the green body microstructure, though neither their ability to flow nor their fill density was as good that of the benchmark submicron powder. The spray-freeze dried powder matched the performance of the benchmark when the solids content was up around $28 \mathrm{vol} \%$, however then the granules were too strong again and did not crush like the spray dried powder. Further work is needed to understand precisely what is giving the granules their strength when the solids content is high and to investigate the potential for producing powders with 
the flow and fill density of the high solids content powders but the strength of the low solids content powders. Nevertheless, reasonably homogeneous nanostructured green bodies could be formed with densities of $\sim 50 \%$ of theoretical.

Whilst gel casting of the nanosuspensions did not work, slip casting was moderately successful in that very homogeneous green bodies could be formed with densities of $\sim 54 \%$ of theoretical. The major limitation was cracking of the bodies during drying and/or organic burn out. If conventional drying was used, the bodies cracked at any solids content greater than $\sim 14$ vol\%; this could be raised to $20 \mathrm{vol} \%$ without cracking being observed if drying was performed at $80 \%$ relative humidity and $25^{\circ} \mathrm{C}$.

Radiant and hybrid-microwave / radiant sintering experiments were performed on both dry and wet processed samples using both single step and two-step sintering cycles. Whilst densities $>98 \%$ of theoretical were achievable by all combinations, an average grain size of $<100 \mathrm{~nm}$ could only be retained using the two-step sintering approach. Whilst with radiant heating the final average grain sizes were approximately $95-100 \mathrm{~nm}$, with the hybrid heating approach they were in the range of $70-80 \mathrm{~nm}$ for die pressed samples and $\sim 65 \mathrm{~nm}$ for the more homogeneous slip cast samples; the latter representing grain growth of just a factor of 4 based on the precursor powder crystallite size. It is believed that the primary advantage offered by the hybrid heating approach is the ability to use a much faster initial heating rate, 20 versus just $7^{\circ} \mathrm{C} \min ^{-1}$, since the bulk of the grain growth observed using this approach occurs during heating to the first sintering temperature, known as T1.

Unlike the work of Chen et $\mathrm{al}^{29}$, who developed the two stage sintering process, the nanostructure did not remain 'frozen' during sintering at T2 but a relatively small amount of grain coarsening was observed at densities above about $97 \%$ of theoretical. This suggests that the mechanisms taking place during the second stage of the sintering process might be similar to those occurring conventionally but shifted to higher densities as a result of the sample after heating to T1 (when the density needs to exceed $\sim 75 \%$ of theoretical for the 2-step sintering approach to work) behaving effectively like a high green density body. Further work is clearly needed and is underway at Loughborough. 
Whilst detailed characterisation of the properties of these nanostructured ceramics has begun now that it is possible to reproducibly produce materials with densities in excess of $99 \%$ of theoretical, there is insufficient space in this paper to report the results. In summary, though, preliminary results suggest that the toughness is reduced and hardness remains essentially unchanged, whilst the wear resistance and resistance to hydrothermal ageing appear to be improved compared to conventional, submicron grain sized 3-YSZ. As a result of detailed crystallographic characterisation it is clear that there is a grain size dependent shift in the phase boundary composition for nano YSZ ceramics leading to 'over stabilisation' at the $3 \mathrm{~mol} \%$ yttria content; work is therefore investigating the effect of yttria content on all of the properties of these nanostructured materials. Finally, in the work to date there has been a fundamental assumption that the goal is to produce ceramics with as fine a grain size as possible. Work has now begun on investigating the properties as a function of the average grain size of the materials to see if there is an optimum value for each property.

\section{Acknowledgements}

The authors would like to thank all members of the current 'nanoceramics' team in IPTME at Loughborough University for their contributions to the developments achieved, including Ketharam Annapoorani, Roshan Aucklah, Susannah Eckhard, Sarah Maude, Anish Paul, Bala Raghupathy, and the new members Rizal Mohammad-Noor and Vinothini Venkatachalam, who are also contributing to obtaining new results. 


\section{Figure Captions}

1. Die pressed barium titanate green body formed from a commercial spray dried nanopowder showing residual agglomerates.

2. The structure of spray-freeze dried agglomerates produced from $3 \mathrm{YSZ}$ nanosuspensions of different initial solids contents at a) low mag and b) high mag; and c) fracture surfaces of bodies die pressed at $380 \mathrm{MPa}$ from the powders.

3. Volumetric flow rate for different spray-freeze dried, spray dried and a benchmark commercial submicron powders.

4. a) Mercury intrusion porosimetry data for green bodies die pressed at $380 \mathrm{MPa}$ from spray-freeze dried and spray dried 3 YSZ nanopowders made from 5 vol\% solids content suspensions.

5. Force deformation plot for 50 spray-freeze dried agglomerates produced from 8 different solid content nanosuspensions. Region A: elastic / plastic deformation of the granules; Point B: fracture of the granules; Region C: deformation of the fractured pieces.

6. Very homogeneous green body, $\sim 54 \%$ of theoretical density, produced by slip casting a 17 vol $\%$ solids content nanosuspension.

7. a) Mercury intrusion porosimetry data for green bodies slip cast from 3YSZ nanosuspensions of two different solids contents and then dried using either humidity drying $\left(80 \%\right.$ rh at $\left.25^{\circ} \mathrm{C}\right)$ or conventional drying at ambient humidity and $25^{\circ} \mathrm{C}$. b) Images of two green bodies produced using the conventional and humidity drying conditions. Note the shine on the surface of the samples; this is typical of the nanostructured ceramics produced by slip casting and is due to the very smooth surfaces formed.

8. a) Grain size versus density of $\mathrm{Y}_{2} \mathrm{O}_{3}$ as a result of two-step sintering, after Chen et al ${ }^{\text {Error! Bookmark not }}$ defined. Note that the authors show the grain size remaining constant in the second sintering step, despite the density increasing to $100 \%$. b) Kinetic window for reaching full density without grain growth for $\mathrm{Y}_{2} \mathrm{O}_{3}$, after Chen et al ${ }^{\text {Error! Bookmark not defined. }}$. Solid symbols reached full density without grain growth. Data above the upper boundary exhibited grain growth; data below the lower boundary did not fully densify.

9. Schematic of the conventional and microwave-hybrid sintering schedules used with nanostructured 3YSZ green bodies. 
10. Grain size versus density plots for nanostructured 3YSZ ceramics produced by single step and twostep sintering using both conventional radiant heating and hybrid-microwave heating.

11. Nanostructures for the ceramic samples highlighted by points $\mathrm{a}, \mathrm{b}$ and $\mathrm{c}$ in figure 10 .

12. Nanostructures at three different points for a $\sim 99.5 \%$ dense $3 \mathrm{YSZ}$ ceramic produced by microwavehybrid sintering. The sintered sample was a disc measuring $10 \mathrm{~mm}$ in diameter by $5 \mathrm{~mm}$ high. 


\section{References}

1 Mayo M. J., Processing Of Nanocrystalline Ceramics From Ultrafine Particles. Int. Mater. Rev., 1996, 41, 85-115.

2 Wakai F., Sakaguchi S. and Matsuno Y., Superplasticity of Yttria-Stabilized. Tetragonal $\mathrm{ZrO}_{2}$ Polycrystals. Adv. Ceram. Mater., 19686, 1, 259-263.

3 Karch J. and Birringer R., Nanocrystalline Ceramics: Possible Candidates For Net-Shape Forming. Ceram. Int., 1990, 16, 291-294.

4 Hahn H. and Averback R. S., Low-Temperature Creep Of Nanocrystalline Titanium(IV) Oxide. J. Am. Ceram. Soc., 1991, 74, [11] 2918-2921.

5 Kuhn W. E., Consolidation Of Ultrafine Particles. In Ultrafine particles (ed. W. E. Kuhn), Wiley New York, 1963, pp 41-103.

6 Karch J., Birringer R. and Gleiter H., Ceramics Ductile At Low Temperature. Nature, 1987, 330, [6148], 556-558.

7 Mayo M. J., Seigel R. W., Narayanasamy A. and Nix W. D., Mechanical Properties Of Nanophase $\mathrm{TiO}_{2}$ As Determined By Nanoindentation. J. Mater. Res., 1990, 5, [5], 1073-1082.

8 Binner J., Vaidhyanathan B. and Liang Y., The Art Of The Possible: Processing Nanostructured Ceramics. Materials World, 2004, 12, 30-32.

9 Groza J. R., Sintering Of Nanocrystalline Powders. Int. J. Powder Met. (USA), 1999, 35, [7], 59-66.

10 Kim H. T., Han Y. H., Sintering Of Nanocrystalline $\mathrm{BaTiO}_{3}$. Ceram. Int., 2004, 30, 1719-1723.

11 Santacruz M. I., Annapoorani K. and Binner J. G. P., Preparation Of High Solids Content Nano Zirconia Suspensions. J Am Ceram. Soc. In Press.

12 Binner J. G. P., Santacruz M. I. \& Annapoorani K., Method for Concentrating Nanosuspensions. International patent application Publ. No. WO 2006/136780 A2, Publ. Date 28/12/06.

13 Tallón C., Moreno R. \& Nieto M. I., Synthesis Of $\gamma-\mathrm{Al}_{2} \mathrm{O}_{3}$ Nanopowders By Freeze-Drying. Mater. Res. Bull., 2006, 41, [8], 1520-1529.

14 Koh Y. H., Song J. H., Lee E. J. \& Kim H. E., Freezing Dilute Ceramic/Camphene Slurry for UltraHigh Porosity Ceramics with Completely Interconnected Pore Networks. J. Am. Ceram. Soc., 2006, 89, [10], 3089-3093. 
15 Takahashi H., Shinohara N., Okumiya M., Uematsu K., Junichiro T., Iwamoto Y. and Kamiya H., Influence Of Slurry Flocculation On The Character And Compaction Of Spray-Dried Silicon Nitride Granules. J. Am. Ceram. Soc., 1995, 78, [4], 903-908.

16 Takahashi H., Shinohara N. and Uematsu K, Influence Of Spray-Dry Slurry Flocculation On The Structure Of Sintered Silicon Nitride. J. Ceram. Soc. Japan., 1996, 104, [1], 59-62.

17 Walker Jr. W. J., Reed J. S. \& Verma S. K., Organic Additive Systems For Spray-Drying And Dry Pressing Silicon Nitride. Ceramic Transactions, 1996, 62, 141-148.

18 Raghupathy B., 2007, Spray Freeze Granulation Of Nano Zirconia Powders, PhD Thesis, Loughborough University, in preparation.

19 Rumpf H., in W.A. Knepper (ed.), The Strength Of Granules And Agglomerates. In Agglomeration, Wiley-Interscience, New York, 1962, pp. 379-418.

20 Mayo M. J., Seidensticker J. R., Hague D. C. and Carim A. H., Surface Chemistry Effects On The Processing And Superplastic Properties Of Nanocrystalline Oxide Ceramics. Nanostructured Materials, 1999, 11, [2], 271-282.

21 Santacruz M. I., Nieto M.I., Binner J. and Moreno R., Gel Casting Of Aqueous Suspensions Of $\mathrm{BaTiO}_{3}$ Nanopowders. Ceramics International, In Press.

22 Lan W. and Xiao P., Constrained Drying Of An Aqueous Yttria-Stabilized Zirconia Slurry On A Substrate II: Binary Particle Slurry. J. Am. Ceram. Soc., 2007, 90, [9], 2771-2778.

23 Groza J. R. and Dowding R. J., Nanoparticulate Materials Densification. Nanostructured Materials, $1996,7,[7]$ 749-768.

24 Rahaman M. N., Sintering And Grain Growth Of Ultrafine $\mathrm{CeO}_{2}$ Powders. In Sintering Technology, (ed. R.M. German, G. L. Messing and R. G. Cornwall), Marcel Dekker, 1996, p93.

25 Hahn H., Averback R. S., Hofler H. J. and Logas J., Sintering And Deformation of Nanocrystalline Ceramics. In Clusters And Cluster-Assembled Materials, eds. R. S. Averback, J. Bernholc and D. L. Nelson, Mater. Res. Symp. Proc. 1991, 206, 569-580.

26 Peelamedu R., Badzian A., Roy R. and Martukanitz R. P., Sintering Of Zirconia Nanopowder By Microwave-Laser Hybrid Process. J. Am. Ceram. Soc., 2004, 87, [9], 1806-1809.

27 Pithan C., Shiratori Y., Waser R., Dornseiffer J. and Haegel F. H., Preparation, Processing, And Characterization Of Nano-Crystalline $\mathrm{BaTiO}_{3}$ Powders And Ceramics Derived From Microemulsion-Mediated Synthesis. J. Am. Ceram. Soc., 2006, 89, [9], 2908-2916. 
28 Lu C., Chang X. H., Qi J. Q., Luo X. J., Wei Q. M., Zhu S., Sun K., Lian J., and Wang L. M., LowTemperature High-Pressure Preparation Of Transparent Nanocrystalline $\mathrm{MgAl}_{2} \mathrm{O}_{4}$ Ceramics. Appl. Phys. Lett., 2006, 88, 213120, 1-3.

29 Chen I. \& Wang X-H., Sintering Dense Nanocrystalline Ceramics Without Final-Stage Grain Growth. Nature, 2000, 404, 168-171.

30 Binner J. G. P. and Vaidhyanathan B., Microwave, Conventional And Hybrid Processing Of Nanostructured Ceramics. Proc. Of Int. Symp. On M’wave Sci. \& Its Appln. to Related Fields, Takamatsu, Japan, 2004, pp 141-144.

31 Lin F. J. T., De Jonghe L. C. and Rahaman. M. N., Microstructure Refinement Of Sintered Alumina By A Two-Step Sintering Technique. J. Am. Ceram. Soc., 1997, 80, [9], 2269-2279.

32 Kim H. D., Han B. D., Park D. S., Lee B. T. and Becher. P. F., Novel Two-Step Sintering Process To Obtain A Bimodal Microstructure In Silicon Nitride. J. Am. Ceram. Soc., 2002, 85, [1], 245252.

33 Wang X-H, Chen P. L. and Chen. I. W., Two-Step Sintering Of Ceramics With Constant Grain-Size, I. $\mathrm{Y}_{2} \mathrm{O}_{3}$. J. Am. Ceram. Soc., 2006, 89, [2], 431-437.

34 Wang X-H., Deng X. Y., Bai H. L., Zhou H., Qu W. G., Li L. T. and Chen. I. W., Two-Step Sintering Of Ceramics With Constant Grain-Size, II: $\mathrm{BaTiO}_{3}$ And Ni-Cu-Zn Ferrite. J. Am. Ceram. Soc., 2006, 89, [2], 438-443.

35 Lee Y. I., Kim Y. W., Mitomo M. and Kim. D. Y., Fabrication Of Dense Nanostructured Silicon Carbide Ceramics Through Two-Step Sintering. J. Am. Ceram. Soc., 2003, 86, [10], 1803-805.

36 Bodišová K., Šajgalík P., Galusek D. and Švančárek P., Two-Stage Sintering Of Alumina With Submicrometer Grain Size. J. Am. Ceram. Soc., 2007, 90 [1] 330-332.

37 Binner J. G. P., Vaidhyanathan B. \& Wang J., A Comparative Study Of Temperature Measurements During Microwave Processing. Proc. of the $9^{\text {th }}$ Int. Conf. on Microwave and High Frequency Heating, Loughborough, UK, 2003, pp 477-480.

38 British Standards, “Advanced Technical Ceramics - Monolithic Ceramics - General Textural Properties" Part 3, BS EN 623-3, 2001, p 10.

39 Wang J., Binner J. G. P., Vaidhyanathan B., Joomun N., Kilner J., Dimitrakis G. \& Cross T. E., Evidence For The Microwave Effect During Hybrid Sintering. J Am Ceram Soc. 2006, 89, [6], 1977-1984. 
40 Wang J., Binner J. G. P., Vaidhyanathan B., Joomun N., Kilner J., Dimitrakis G. \& Cross T. E., Evidence For The Microwave Effect During The Annealing Of Zinc Oxide. J Am Ceram Soc., 2007, 90, [9], 2693-2697. 


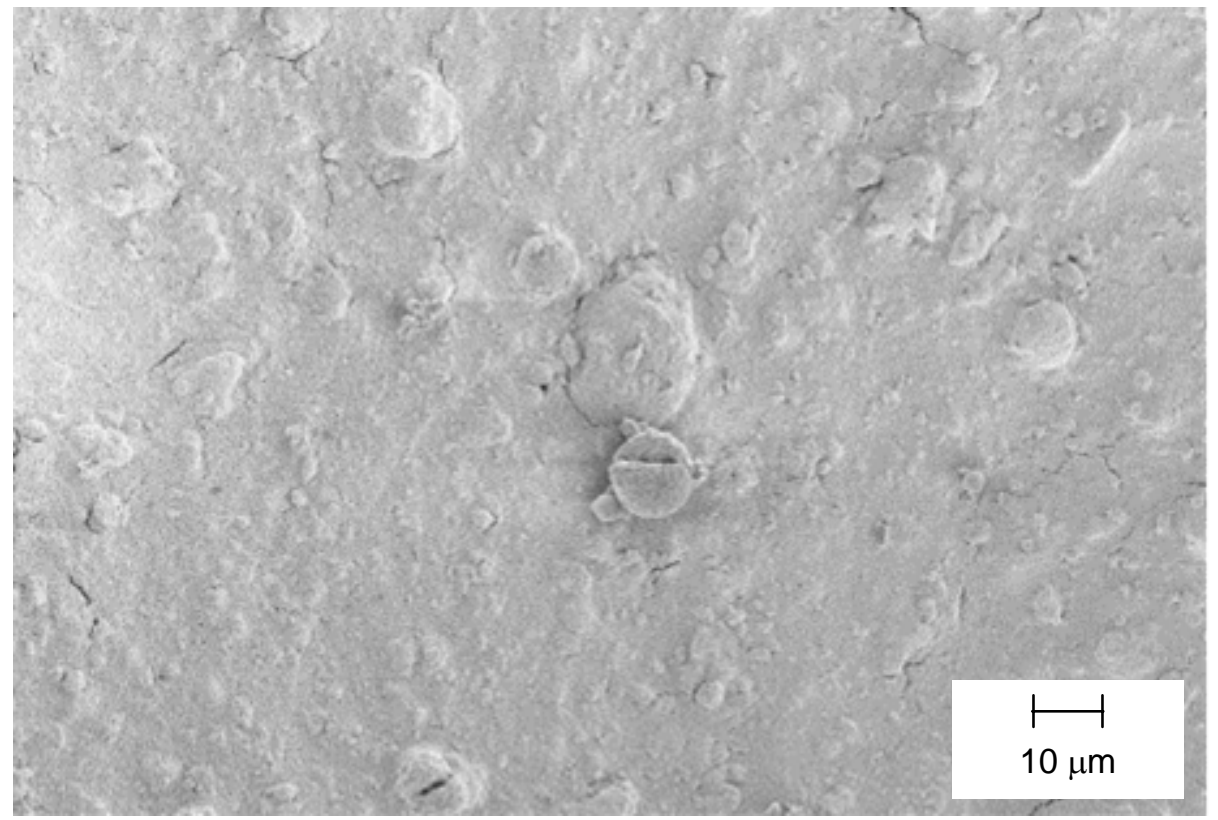

Fig 1 
5 vol\% suspension

a

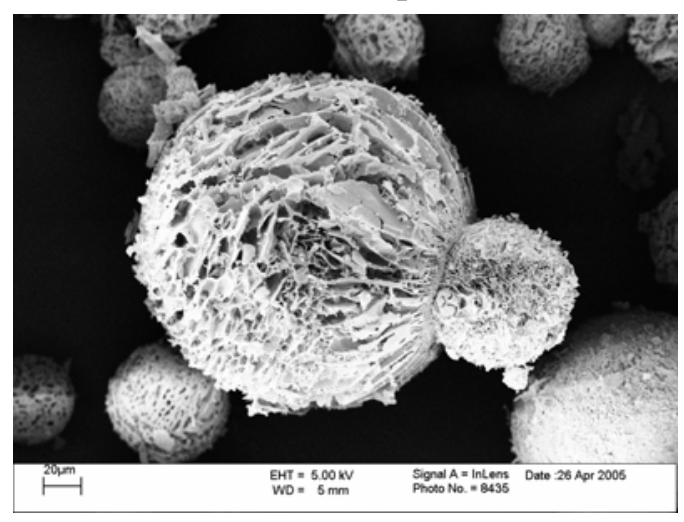

b
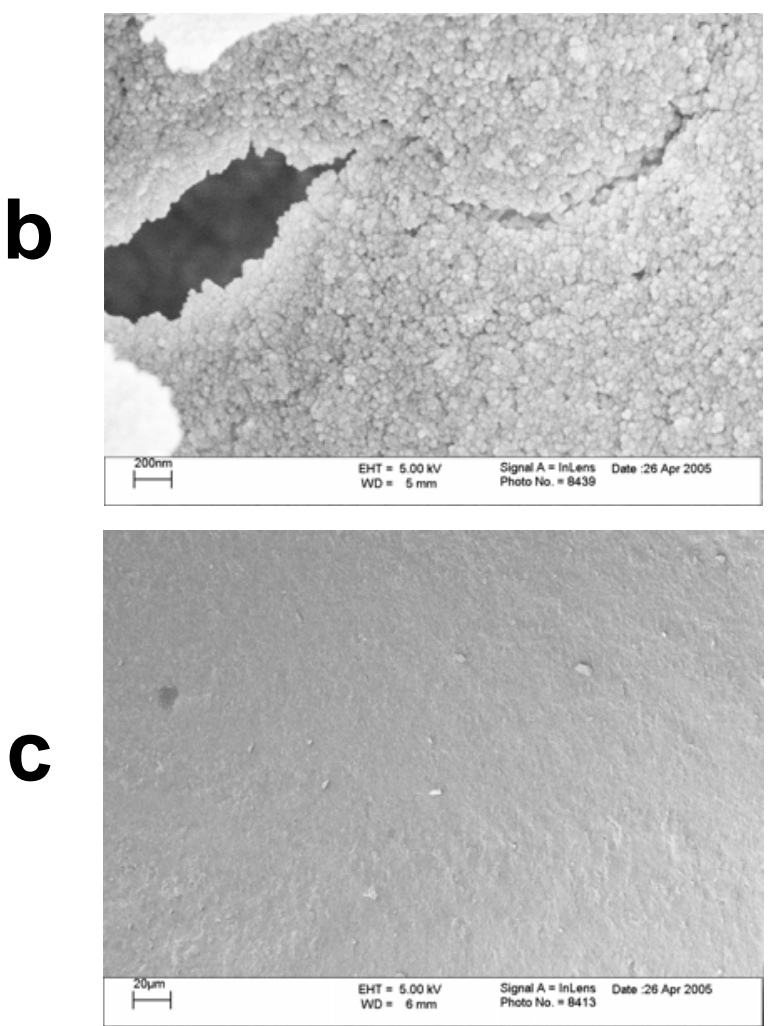

14 vol\% suspension
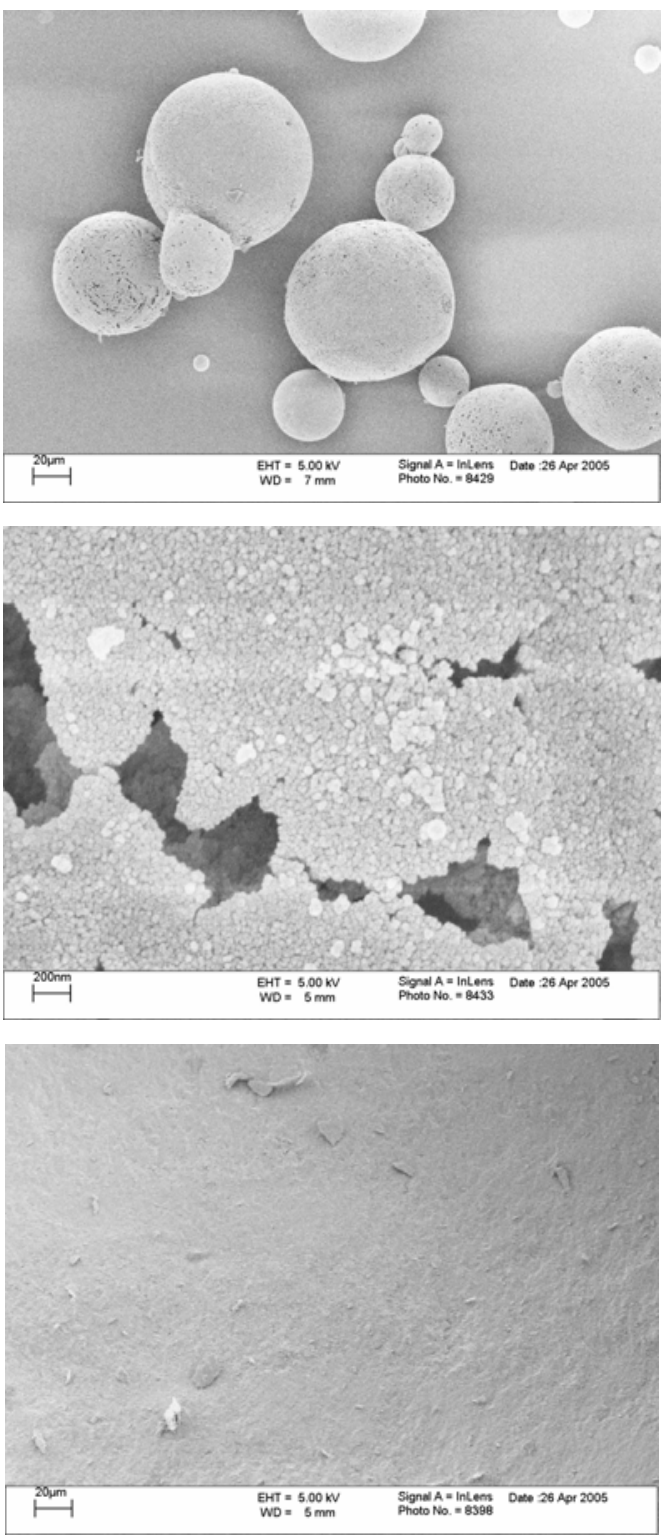

28 vol\% suspension
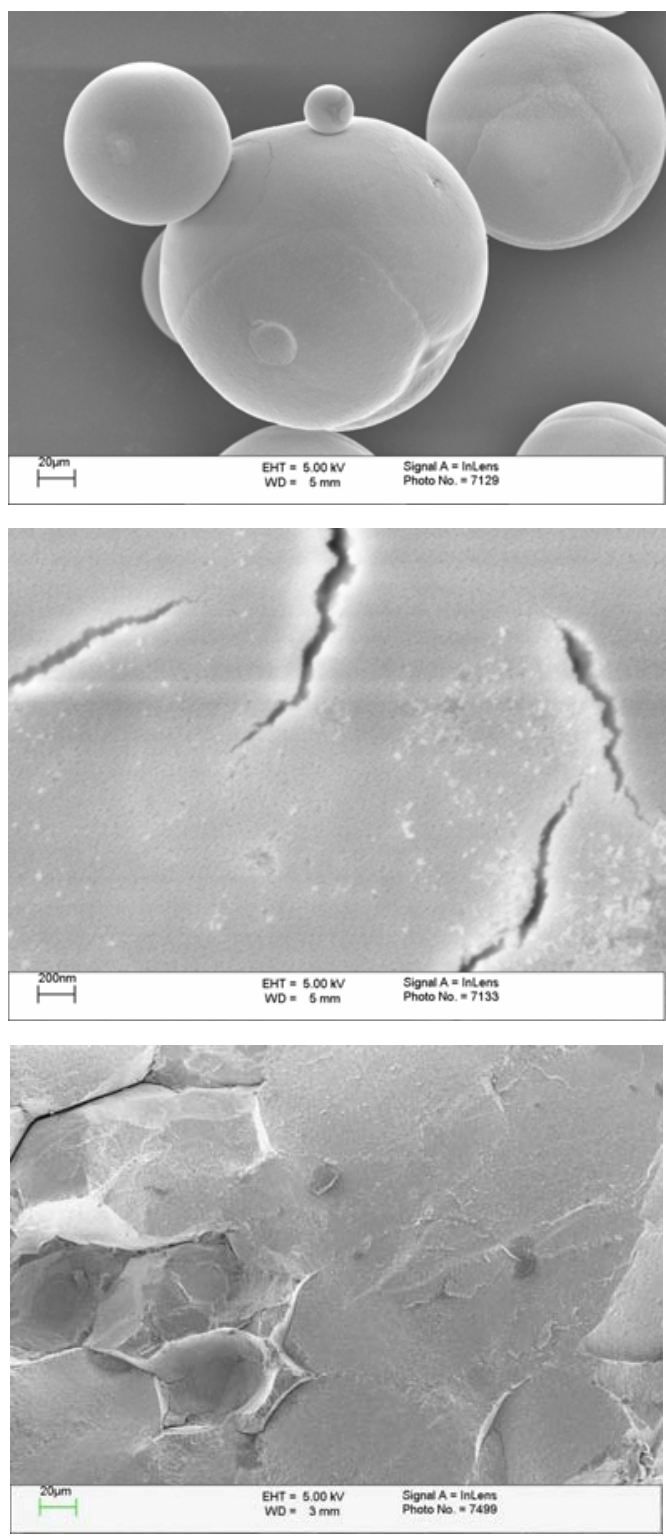

Fig 2 


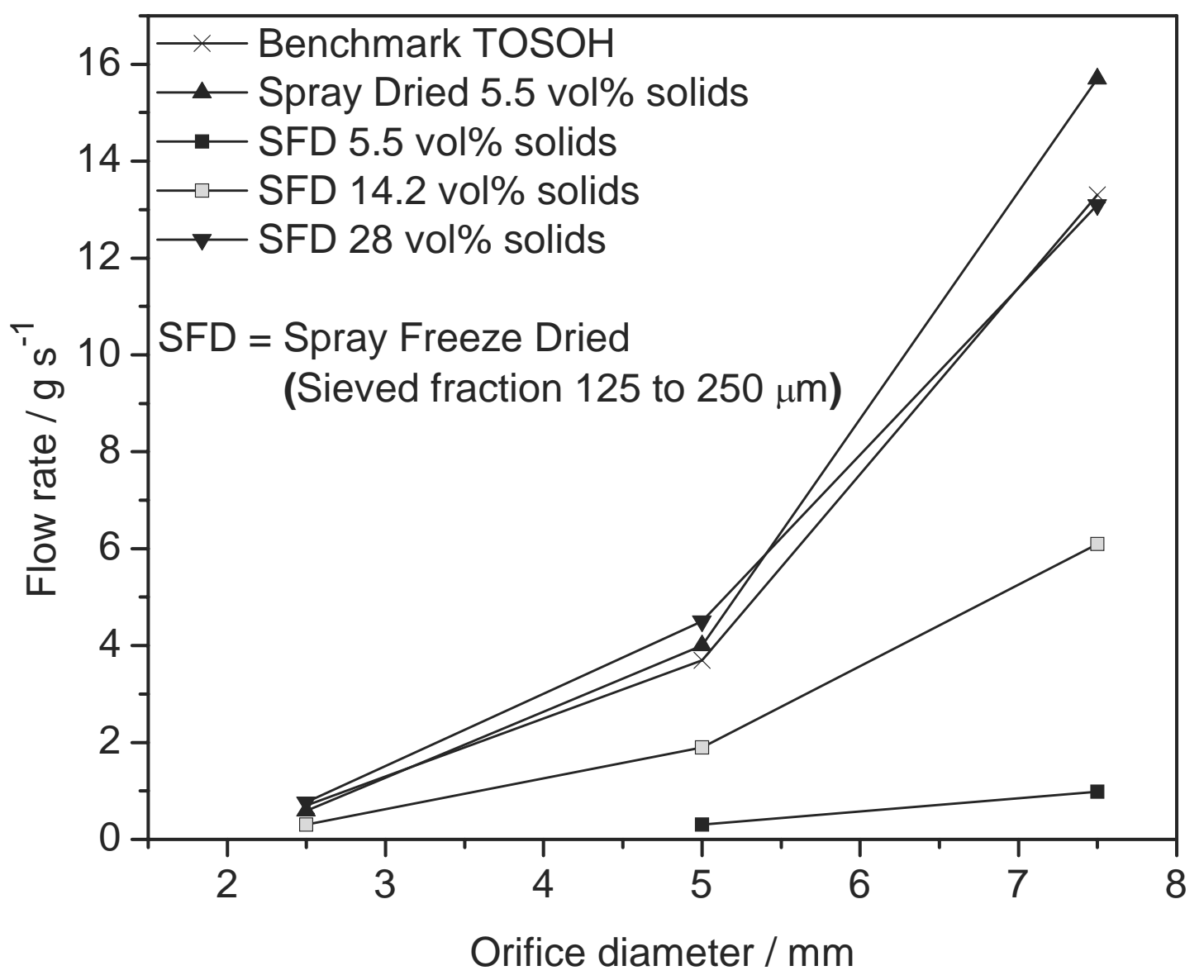

Fig 3 


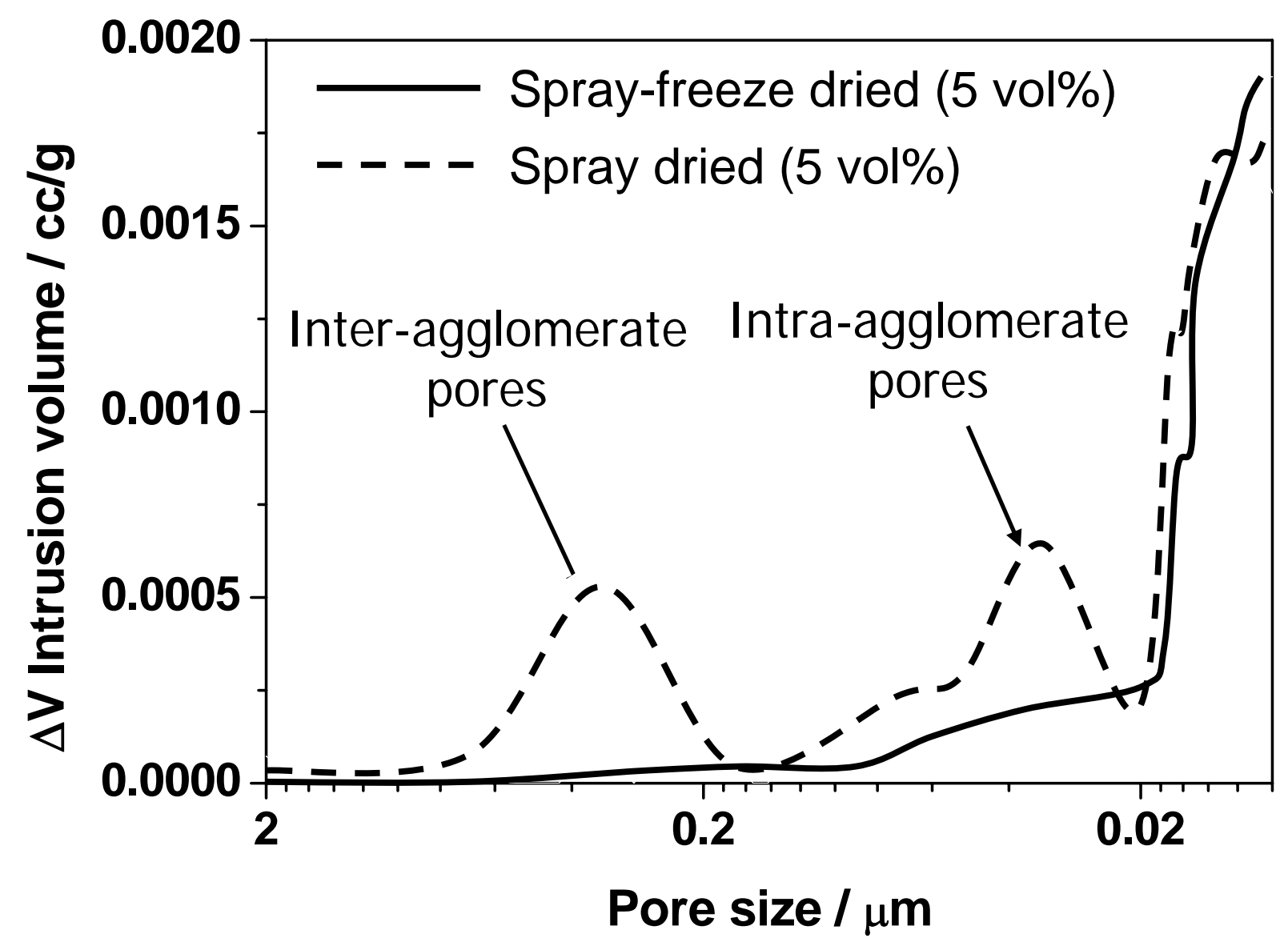

a

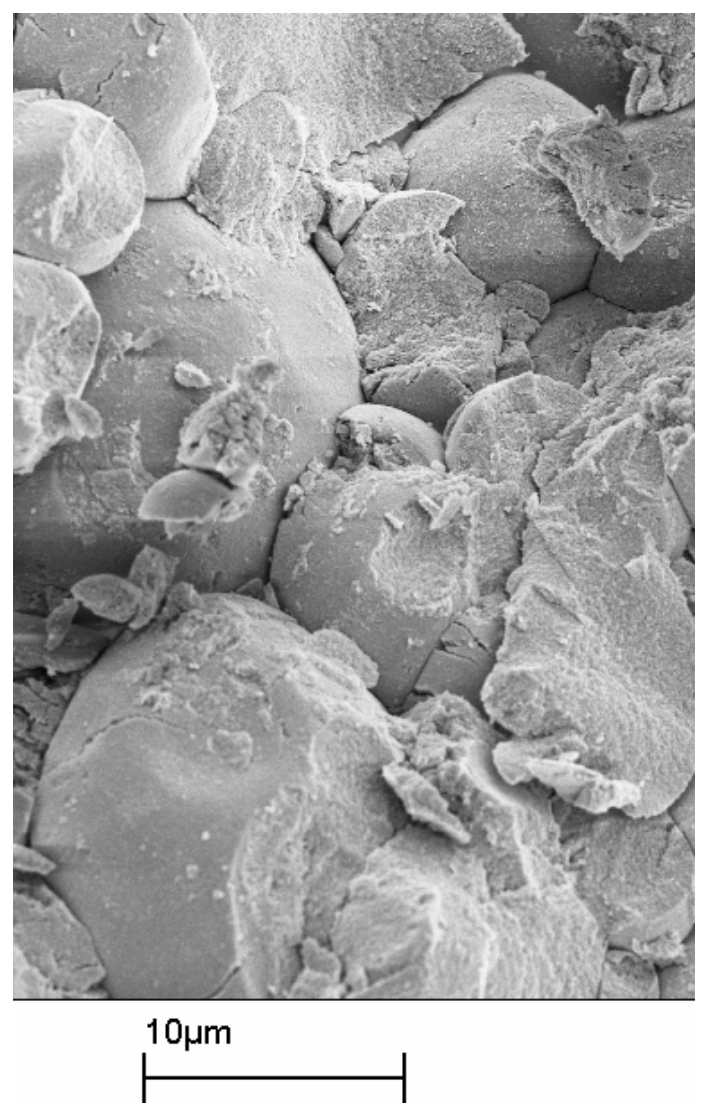

b

Fig 4 


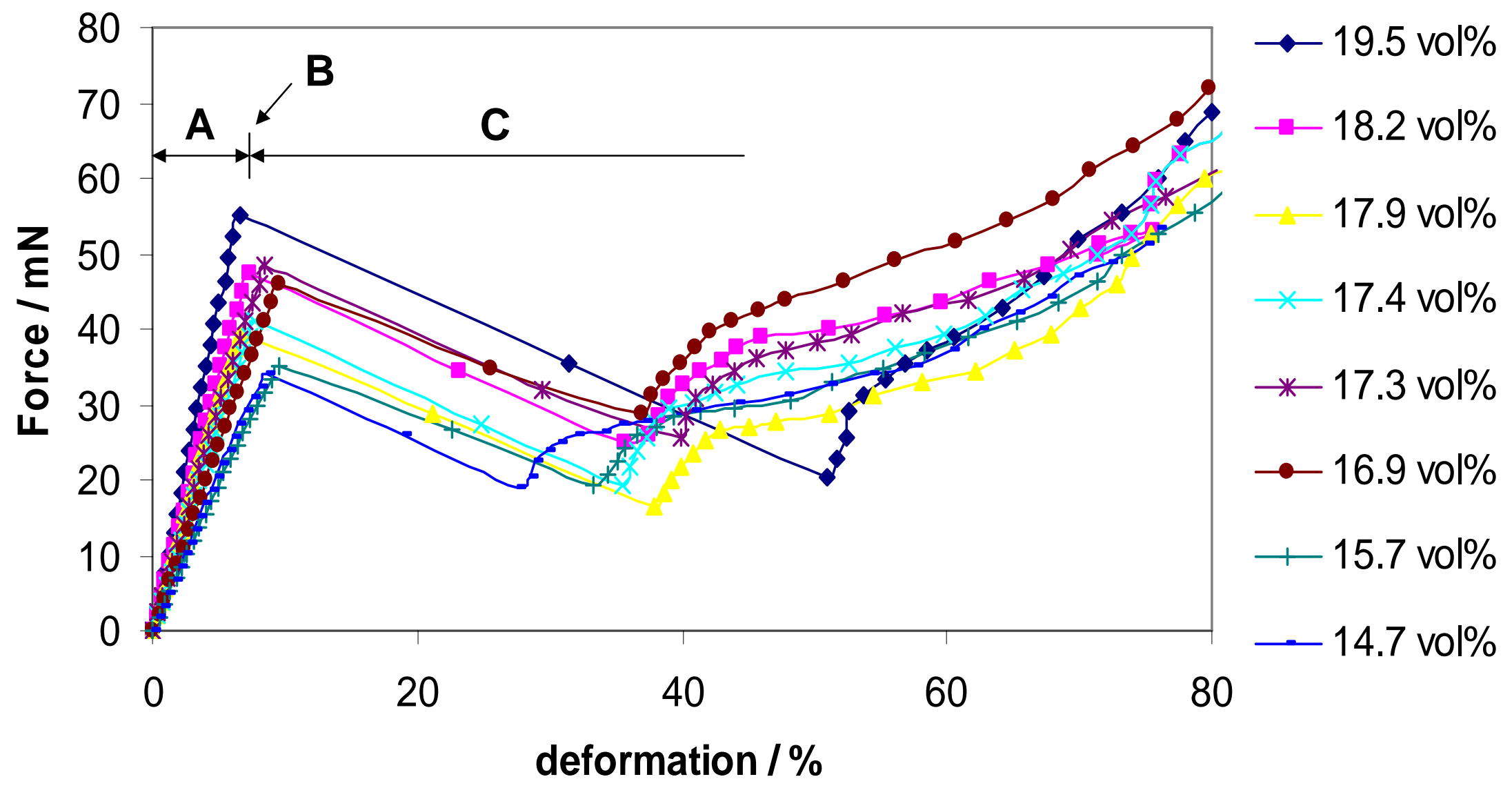




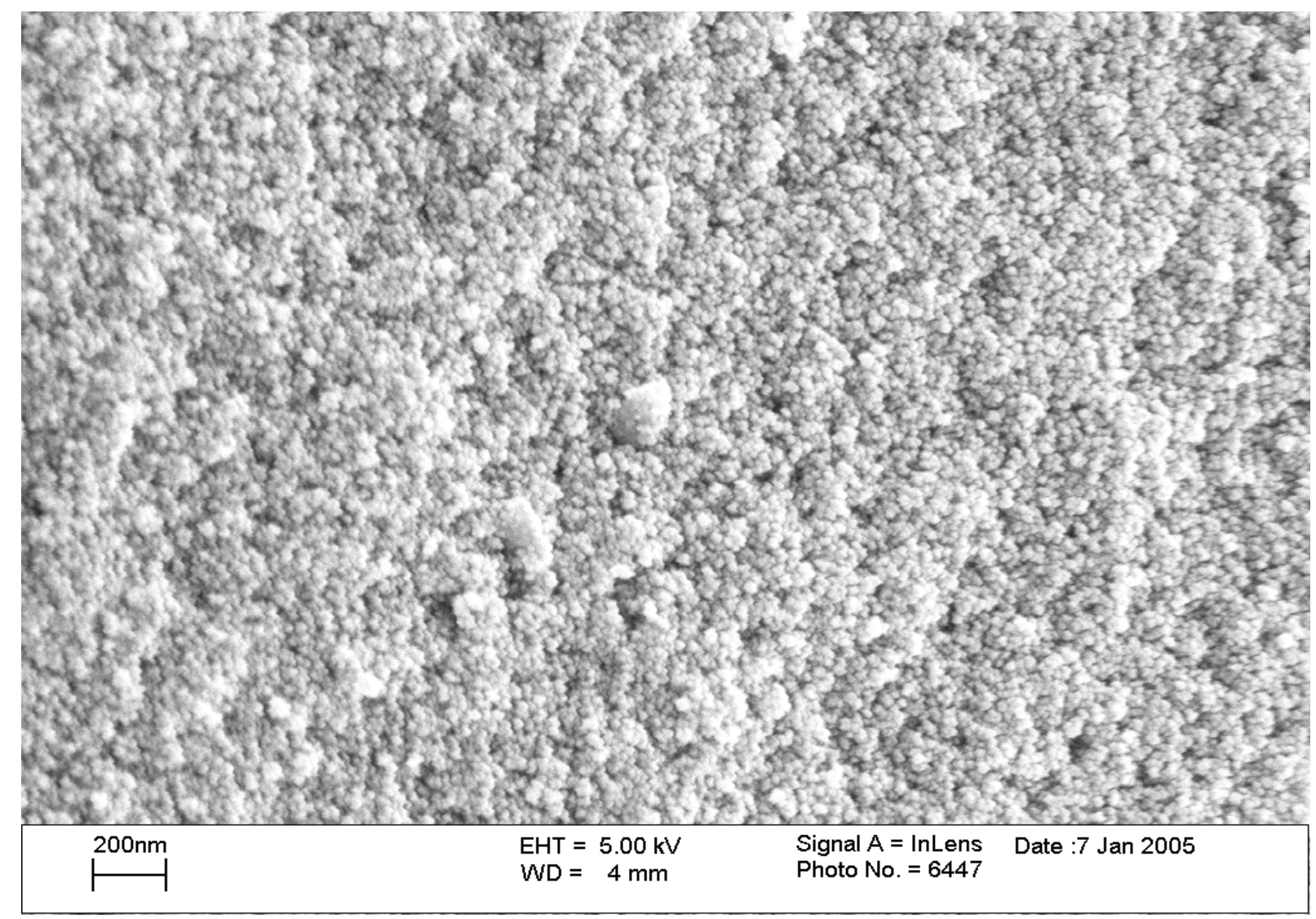

\section{Fig 6}



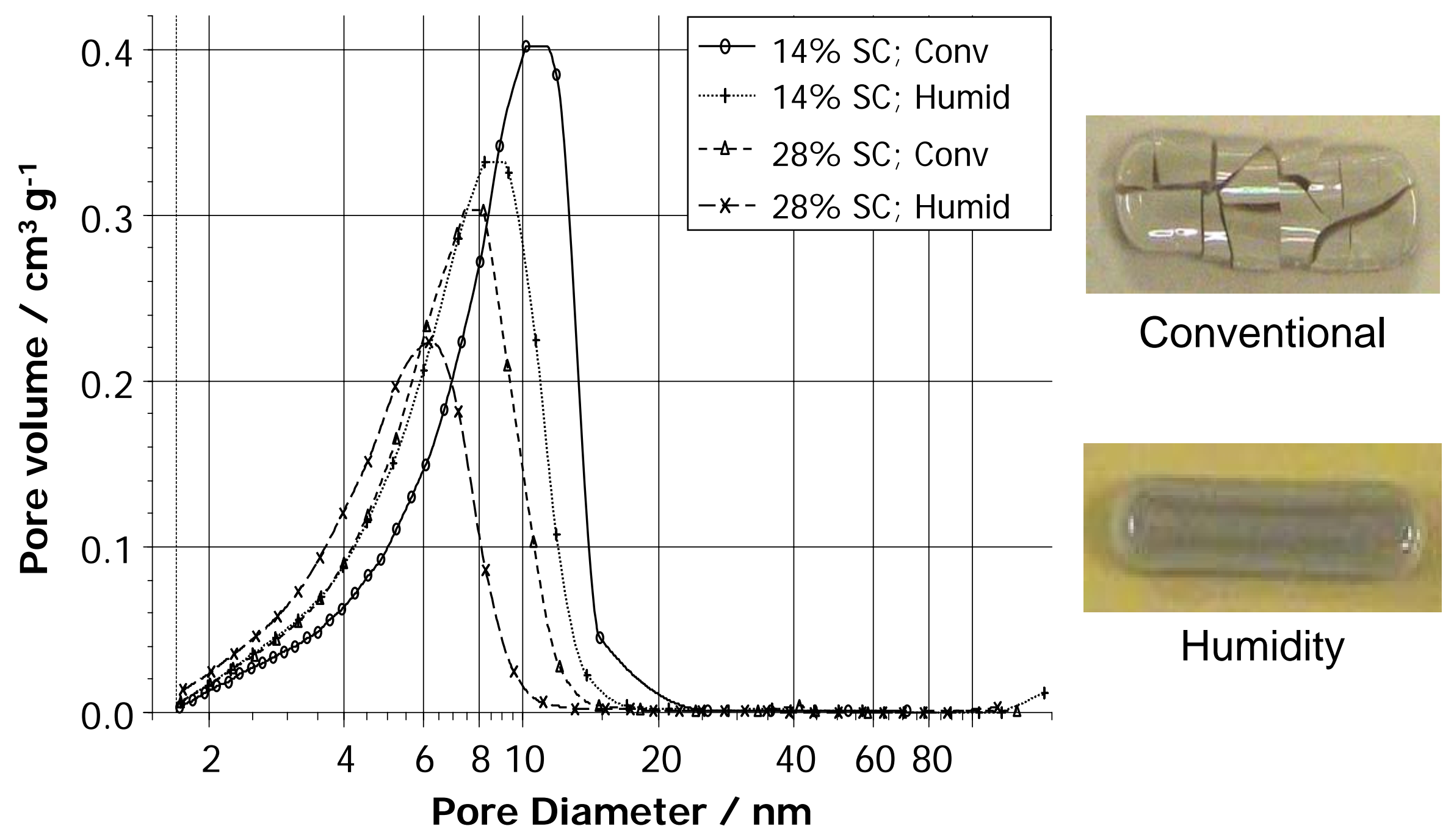

Conventional

Humidity

a

b

\section{Fig 7}




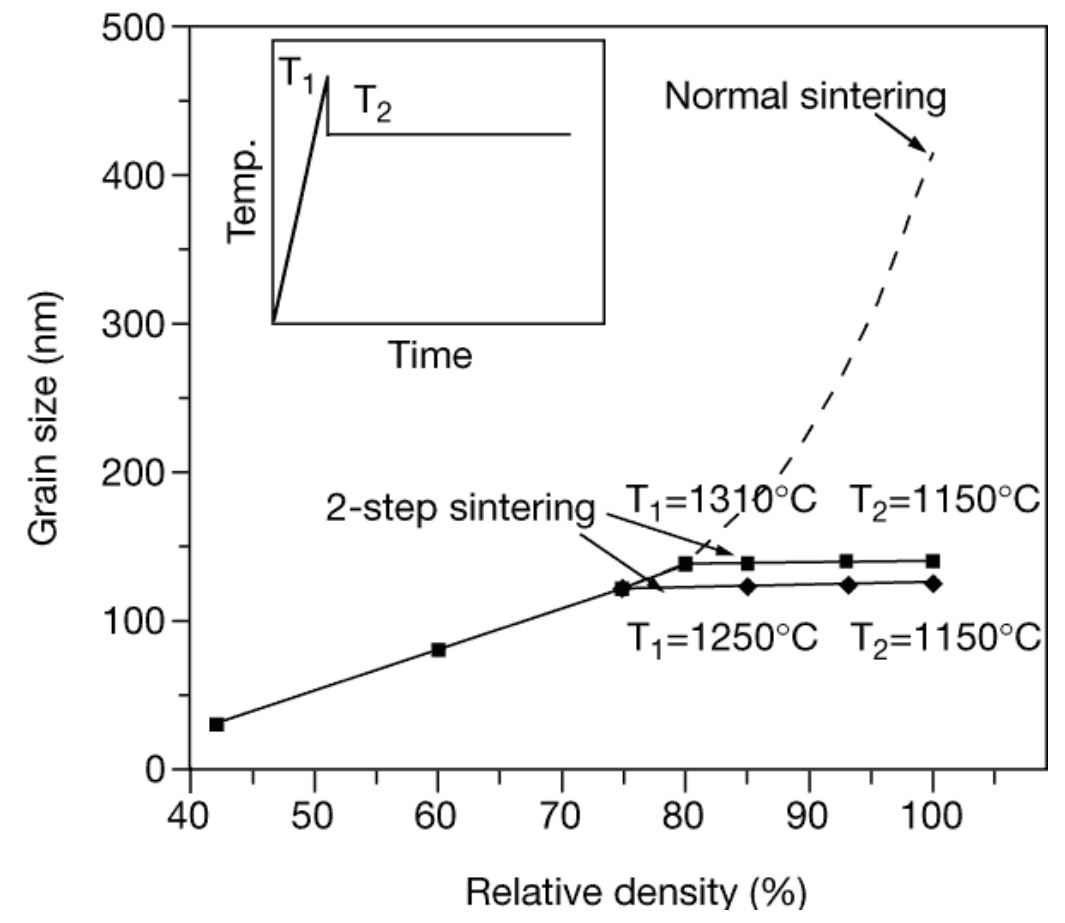

a

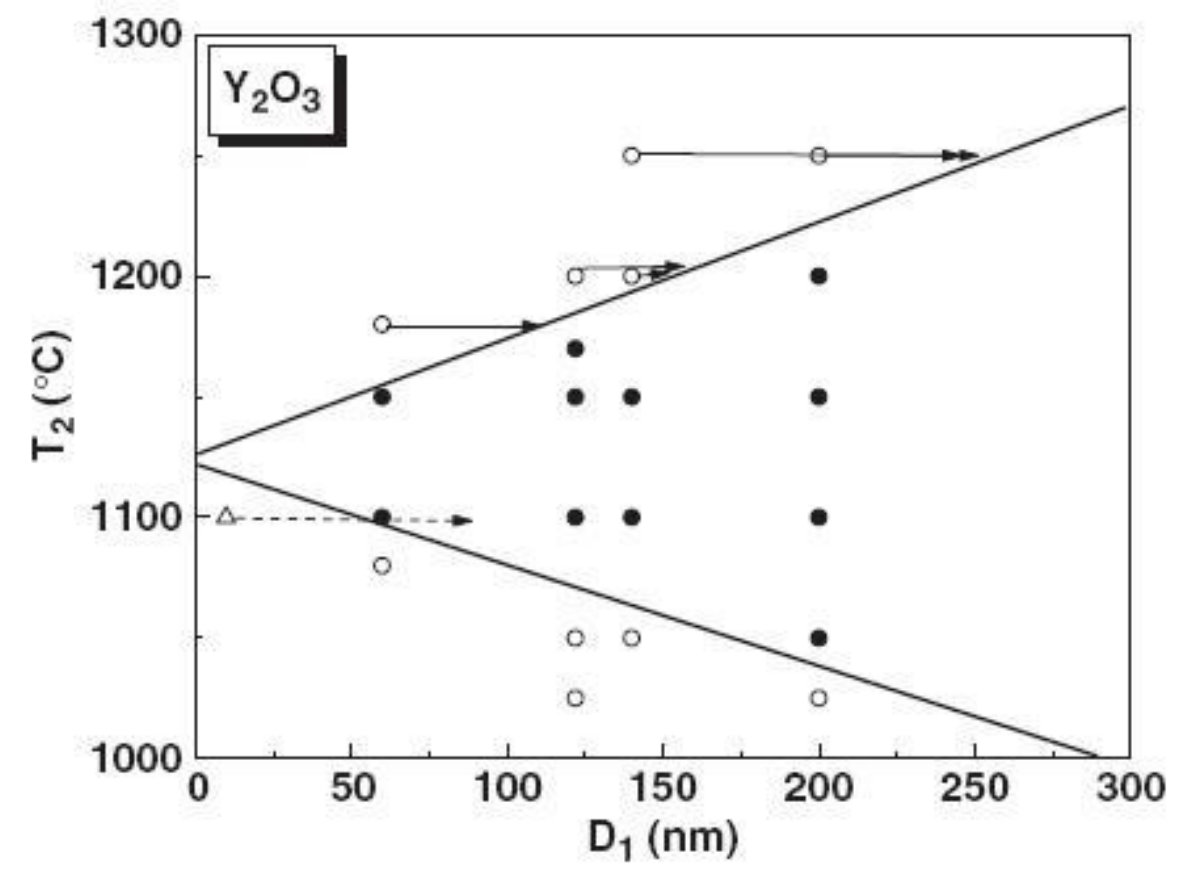

b

\section{Fig 8}




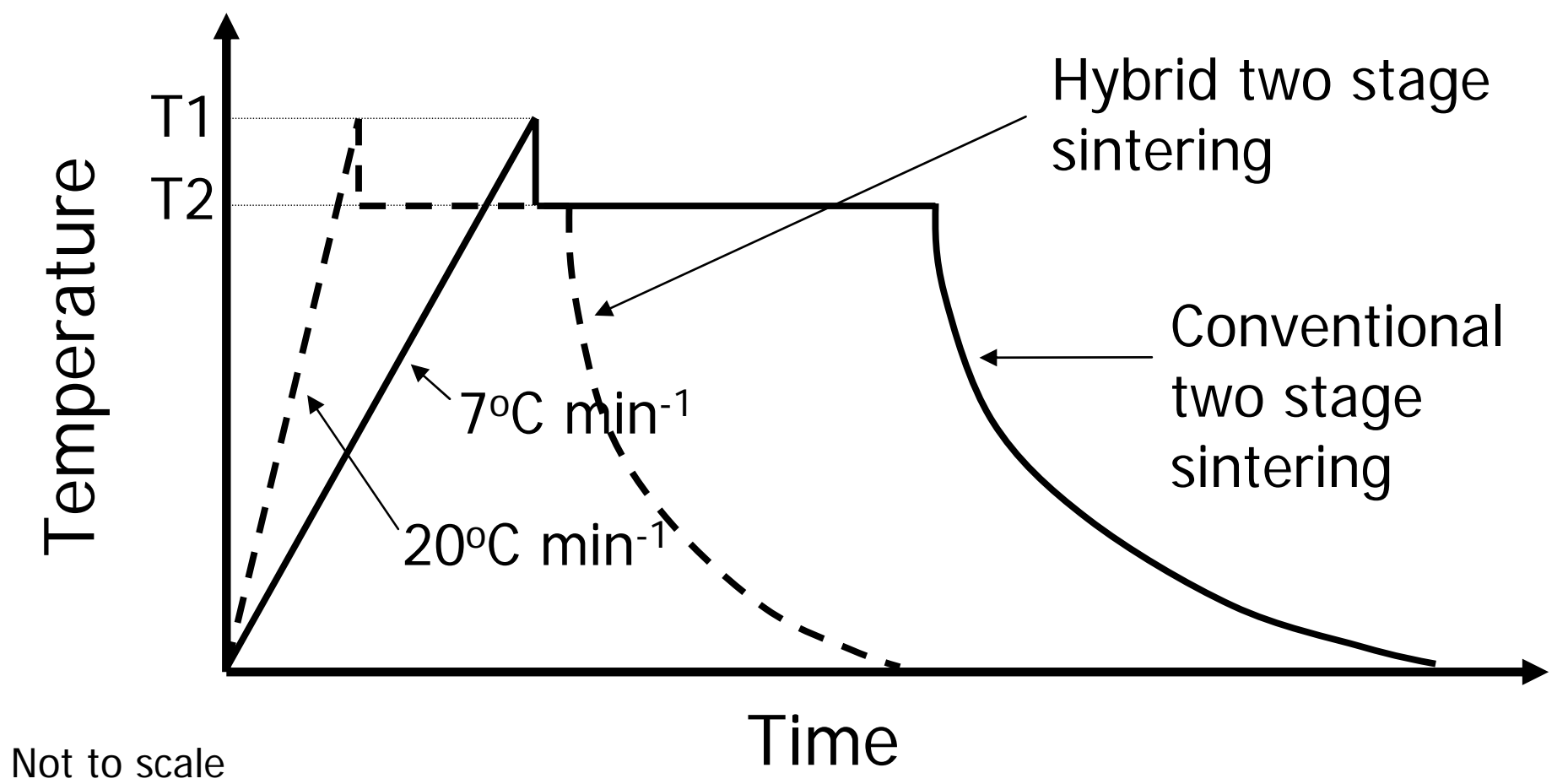

Fig 9 


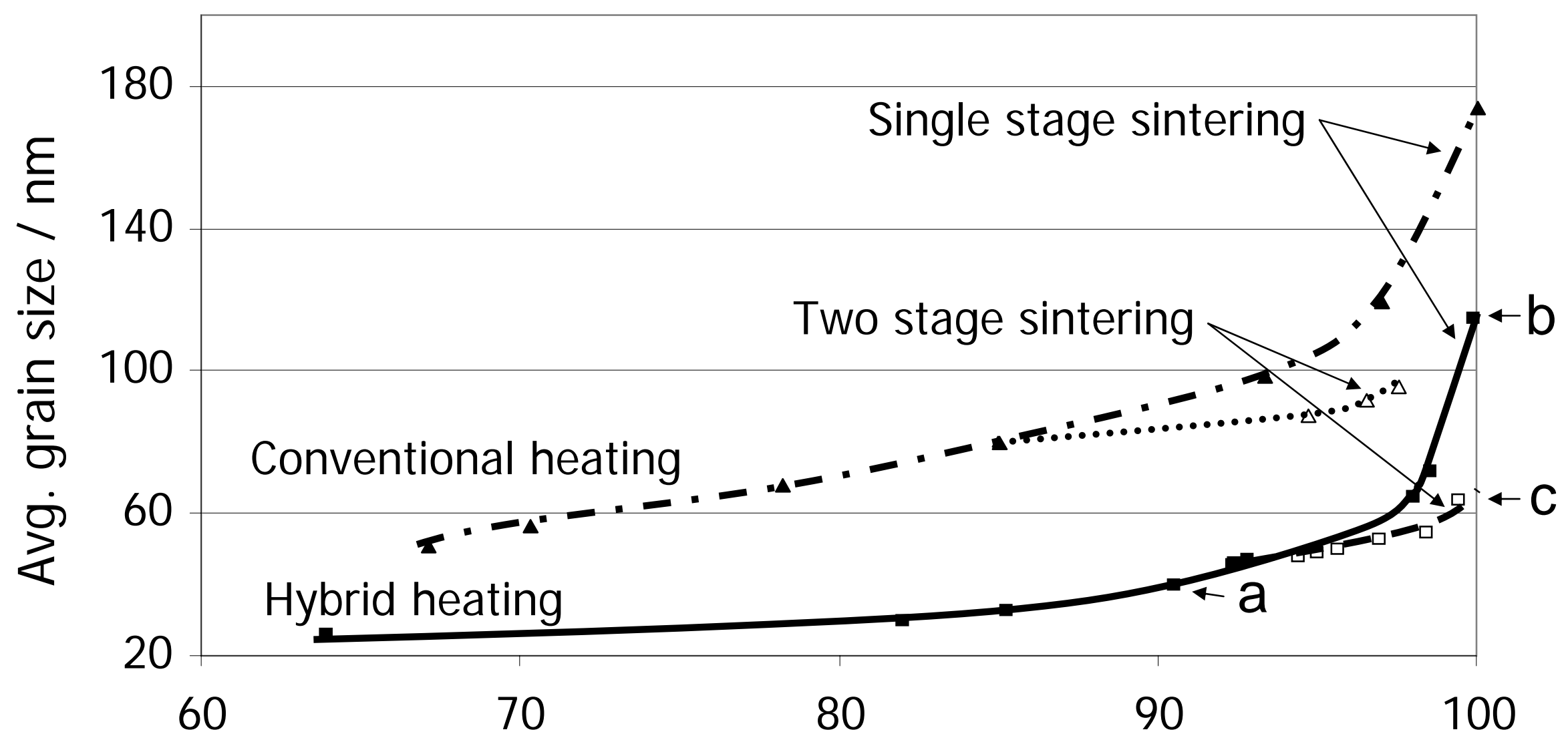

Density / \%TD 


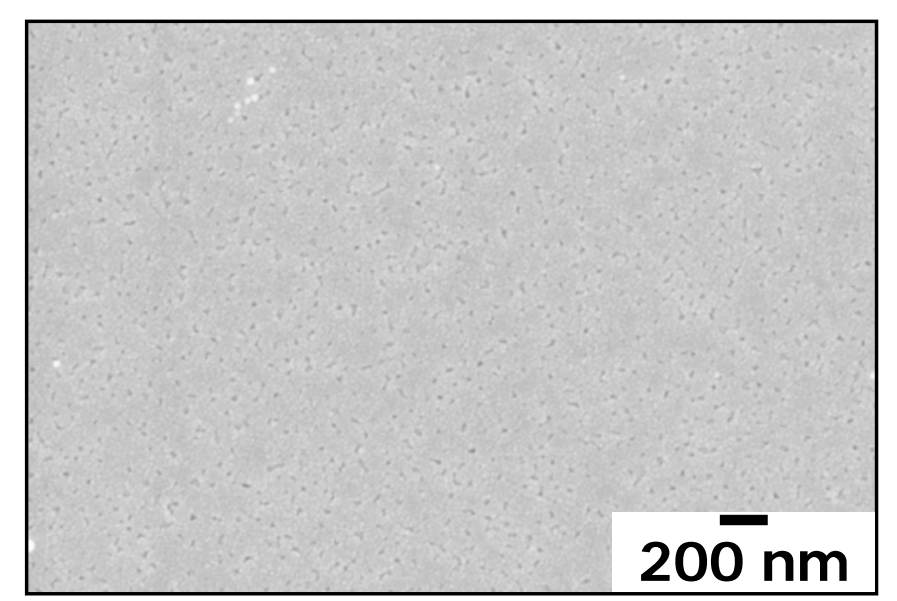

a

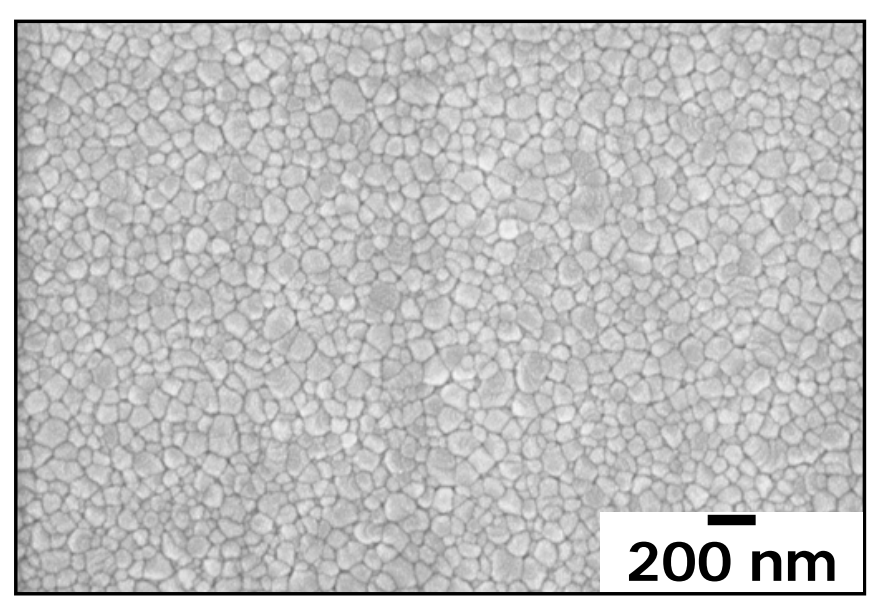

b

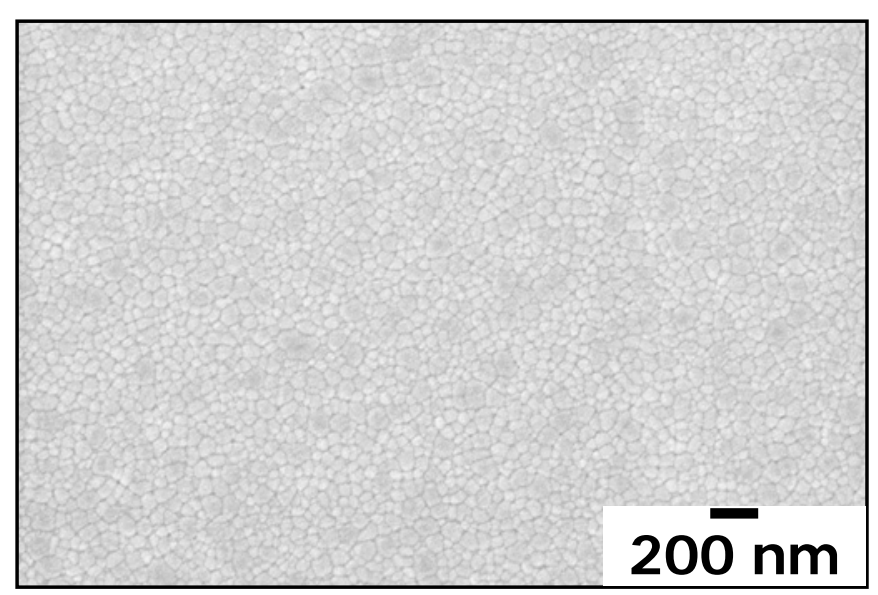

Fig 11

C 


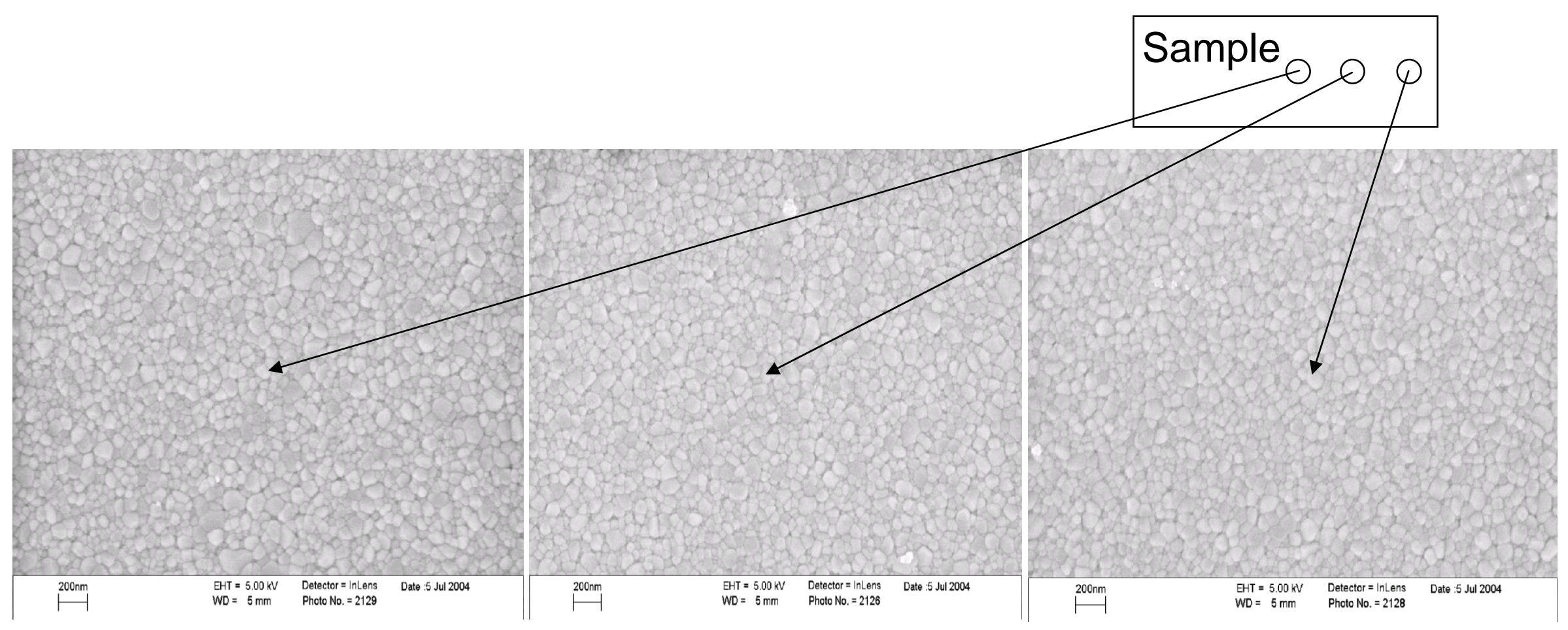

Fig 12 